\title{
Application of S,N-Chelating Chiral Zinc Bis(aminoarenethiolates) as New Precursor Catalysts in the Enantioselective Addition of Dialkylzincs to Aldehydes ${ }^{\dagger}$
}

\author{
Evelien Rijnberg, ${ }^{\ddagger}$ Neldes J . Hovestad, ${ }^{\ddagger}$ Arjan W. Kleij,, \\ J ohann T. B. H. J astrzebski, ${ }^{\ddagger}$ J aap Boersma, ${ }^{\ddagger}$ Maurits D. J anssen, $\neq$ \\ Anthony L. Spek, $\$$ and Gerard van Koten*, \\ Debye Institute, Department of Metal-Mediated Synthesis, and Bijvoet Center for \\ Biomolecular Research, Crystal and Structural Chemistry, Utrecht University, Padualaan 8, \\ $3584 \mathrm{CH}$ Utrecht, The Netherlands \\ Received February $26,1997^{\circledR}$
}

\begin{abstract}
A new enantiomerically pure S,N-chelated zinc bis(aminoarenethiolate), (R, R)- $\mathrm{Zn}\left(\mathrm{SC}_{6} \mathrm{H}_{4} \mathrm{C}\right.$ $\left.(\mathrm{Me}) \mathrm{HNMe}_{2}-2\right)_{2}((\mathrm{R}, \mathrm{R})-3 \mathbf{b})$, has been synthesized by the reaction of the (R)-trimethylsilyl aminoarenethiolate species ( $R$ )-2b with $\mathrm{ZnCl}_{2}$ in a 2:1 molar ratio. ( $\left.R, R\right)-\mathbf{3 b}$ is an efficient catalyst for the addition of dialkylzinc compounds to aliphatic and aromatic aldehydes to give the corresponding secondary al cohols in nearly quantitative yiel ds with optical purities of 69-99\% ee under mild reaction conditions. Although excellent selectivities were obtained with this simple ligand containing only one ster eogenic (carbon) center, further modifications of the amino substituents were studied. Cyclic $\mathrm{N}\left(\mathrm{CH}_{2}\right)_{4}$ or $\mathrm{N}\left(\mathrm{CH}_{2}\right)_{5}$ amino-substituted aminoarenethiolate ligands considerably enhanced the reaction rates, resulting in shorter reaction times and higher ee's. The mechanism of these 1,2-addition reactions has the general characteristics as reported by Noyori et al. This conclusion is based on the synthesis, isolation, and characterization (X-ray, ${ }^{1} \mathrm{H}$ and ${ }^{13} \mathrm{C} \mathrm{NMR}$ ) of the enantiopure zinc bis(aminoarenethiolate) and organozinc aminoarenethiolate intermediates and on monitoring of the reaction process. We present evidence for an interpretation of the binding in the product-forming key intermediate complex in terms of an organozinc cation/anion pair. The possibility that the very efficient transfer of chiral information in this compact complex may be due to a combination of the shortness of the $\mathrm{Zn}-\mathrm{N}$ coordinate bonds with concomitant $\eta^{2}$ bonding of the aldehyde substrate is discussed. The solid-state structure of the zinc bis(aminoarenethiolate) $(\mathrm{R}, \mathrm{R})-\mathrm{Zn}\left(\mathrm{SC}_{6} \mathrm{H}_{4} \mathrm{C}(\mathrm{Me}) \mathrm{HNMe}_{2}-2\right)_{2}$ is reported.
\end{abstract}

\section{Introduction}

The discovery of the synthesis of optically active secondary alcohols by enantiosel ective addition of diorganozinc compounds to aldehydes by Mukaiyama ${ }^{1}$ and Oguni $^{2}$ initiated a search for the ultimate catalyst system that made this enantioselective 1,2-addition one of the best studied reactions. In most cases, the chiral catalyst systems consist of in situ prepared organozinc derivatives of amino alcohols, piperazines, or diols, although also boron and titanium complexes have been reported. ${ }^{3}$ The most successful catalyst systems comprise a $\beta$-amino alkoxide skeleton in which generally two chiral carbon atoms are present, that forms a five-

* To whom correspondence should be addressed.

† Dedicated to the memory of Prof. Dr. W. Oppolzer, in admiration of his pioneering research in enantioselective organic synthesis.

‡ Debye Institute, Department of Metal-Mediated Synthesis.

$\S$ Bijvoet Center for Biomolecular Research, Crystal and Structural Chemistry. Address correspondence concerning crystallography to this author.

$\otimes$ Abstract published in Advance ACS Abstracts, May 15, 1997

(1) Mukaiyama, T.; Soai, K.; Kobayashi, S. Chem. Lett. 1978, 219. (b) Soai, K.; Mukaiyama, T. Chem. Lett. 1978, 491. (c) Sato, T.; Soai, K.; Suzuki, K.; Mukaiyama, T. Chem. Lett. 1978, 601. (d) Mukaiyama, T.; Soai, K.; Shimizu, H.; Suzuki, K. J . Am. Chem. Soc. 1979, 101, 1455.

(2) Oguni, N.; Omi, T. Tetrahedron Lett. 1984, 25, 2823.

(3) Reviews: (a) Noyori, R.; Kitamura, M. Angew. Chem., Int. Ed. Engl. 1991, 30, 49. (b) Soai, K.; Niwa, S. Chem. Rev. 1992, 92, 833. membered chelate ring when bonded to a metal center. Although it is difficult to match or even to surpass the success of the application of 3-exo-(dimethylamino)isoborneol (DAIB) ${ }^{4}$ and (di-n-butylamino)norephedrine $(D B N E),{ }^{5}$ the quest remains for the development of alternative, better (i.e. cheaper), and more accessible ligand systems.

In recent years, we developed the first chiral monoanionic aminoarenethiolate ligand, (R)-2-[1-(dimethylamino)ethyl]thiophenolate. ${ }^{6}$ The optically pure ligand is easily accessible from (1-phenylethyl)amine, which is commercially available in both enantiomeric forms. Besides its low price, the aminoarenethiol ate ligand has the advantage that substituents can easily be introduced either at the amino functional group or in the aromatic ring. ${ }^{7}$

(4) (a) Kitamura, M.; Suga, S.; Kawai, K.; Noyori, R. J . Am. Chem Soc. 1986, 108, 6071. (b) Kitamura, M.; Okada, S.; Suga, S.; Noyori, R. M. J . Am. Chem. Soc. 1989, 111, 4028. (c) Noyori, R.; Suga, S.; Kawai, K.; Okada, S.; Kitamura, M.; Oguni, N.; Hayashi, M.; Kaneko, T.; Matsuda, Y. J . Organomet. Chem. 1990, 382, 19. (d) Kitamura, M.; Suga, S.; Niwa, M.; Noyori, R. J . Am. Chem. Soc. 1995, 117, 4832.

(5) (a) Soai, K.; Y okoyama, S.; Ebihara, K.; Hayasaka, T. j . Chem. Soc., Chem. Commun. 1987, 1690. (b) Soai, K.; Yokayama, S.; Hayasaka, T. J . Org. Chem. 1991, 56, 4264.

(6) Reviews: (a) van Koten, G. J . Organomet. Chem. 1990, 400, 283. (b) van Koten, G. Pure Appl. Chem. 1994, 66, 1455.

(7) Kleijn, H.; van Cranenbroek, J. A. W. M.; Rijnberg, E.; J astrzebski, J . T. B. H.; van Koten, G. Manuscript in preparation. 


$$
\begin{array}{ll}
R^{\prime}=H ; R^{\prime \prime}=M e(a) \\
R^{\prime}=M e ; R^{\prime \prime}=M e(b) \\
R^{-} & R^{\prime}=M e ; R^{\prime \prime}=\left(\mathrm{CH}_{2}\right)_{4}(\mathbf{c}) \\
R^{\prime}=M e ; R^{\prime \prime}=\left(\mathrm{CH}_{2}\right)_{5}(\mathbf{d})
\end{array}
$$

Figure 1. Aminoarenethiolate ligands used in this work.

By using a soluble copper (I) aminoarenethiolate catalyst, we were able to control the regio-, chemo-, and stereosel ectivity in a variety of reactions such as 1,4additions of organometallic reagents to $\alpha, \beta$-unsaturated ketones, $^{8 a-c} 1,6$-additions of such reagents to enyne esters, ${ }^{8 d}$ and $\alpha$ - or $\gamma$-coupling reactions to allylic substrates. ${ }^{8 e, f}$ The promising results obtained with the aminoarenethiolate ligand system in these copper(I )catalyzed enanti oselective carbon-carbon coupling reactions prompted us to apply such ligands ${ }^{6}$ also in zinccatalyzed 1,2-addition reactions.

Recently, we published our initial results in this field ${ }^{9}$ and in this paper we present the full study of the zinc aminoarenethiolate complexes that have been used as precursor catalysts and as intermediates in these reactions. These complexes catalyze the quantitative alkyl transfer of di organozinc compounds to various aromatic and aliphatic aldehydes to give the corresponding secondary alcohols with optical purities of up to $99 \%$ ee under mild conditions. ${ }^{9}$ Since it had been shown earlier ${ }^{5}$ that the chiral induction depends on the nature of the substituents on the nitrogen atom of the alkoxide ligand in the zinc catalyst, we also investigated the influence of different $R^{\prime}$ and $R^{\prime \prime}$ substituents in the aminoarenethiolate (see Figure 1). The pyrrolidinyl and piperidinyl derivatives of the aminoarenethiolate ligand were used to test the effects of the introduction of ringcontaining substituents in these catalysts.

\section{Results}

Synthesis of the (Precursor) Catalysts. The parent $\mathrm{N}, \mathrm{N}^{\prime}$-dimethyl-substituted (1-phenylethyl)amines $\mathrm{C}_{6} \mathrm{H}_{5} \mathrm{CH}\left(\mathrm{R}^{\prime}\right) \mathrm{NMe}_{2}\left(\mathrm{R}^{\prime}=\mathrm{H}, \mathrm{Me}\right)$ are commercially available or are easily prepared by Clarke-Eschweiler methylation of the primary amine. The other $\mathrm{N}, \mathrm{N}^{\prime}-$ disubstituted (R)-1-phenylethylamines (R)- $\mathrm{C}_{6} \mathrm{H}_{4} \mathrm{CH}$ (Me)NR" $2\left(\mathrm{R}_{2}{ }_{2}=\left(\mathrm{CH}_{2}\right)_{4},\left(\mathrm{CH}_{2}\right)_{5}\right)$ were prepared by reaction of (R)- $\mathrm{C}_{6} \mathrm{H}_{4} \mathrm{CH}(\mathrm{Me}) \mathrm{NH}_{2}$ with 2 equiv of the appropriate alkyl halides in the presence of an excess of $\mathrm{NaHCO}_{3}$ in refluxing dmf. The reaction of the tertiary amines with $\mathrm{n}$ - or t-BuLi in pentane afforded the ortho-lithiated derivatives $\left[\mathrm{Li}\left(\mathrm{C}_{6} \mathrm{H}_{4} \mathrm{CH}\left(\mathrm{R}^{\prime}\right) \mathrm{NR}^{\prime \prime}{ }_{2-}\right.\right.$ 2) $]_{4}{ }^{10}$

To exclude the presence of lithium salts in the final zinc aminoarenethiolates, the ortho-lithiated amines were reacted with $1 / 8$ equiv of $S_{8}$ in thf with vigorous stirring to give the corresponding lithium aminoarene-

(8) (a) Lambert, F ; Knotter, D. M.; J anssen, M. D.; van Klaveren, M.; Boersma, J .; van Koten, G. Tetrahedron: Asymmetry 1991, 2, 1097. (b) Knotter, D. M.; Grove, D. M.; Smeets, W. J . J .; Spek, A. L.; van Koten, G. J . Am. Chem. Soc. 1992, 114, 3400. (c) van Klaveren, M.; Lambert, F.; Eijkelkamp, D. J . F. M.; Grove, D. M.; van Koten, G. Tetrahedron Lett. 1994, 35, 6135. (d) Haubrich, A.; van Klaveren, M.; van Koten, G.; Handke, G.; Krause, N. J . Org. Chem. 1993, 58, 5849. (e) van Klaveren, M.; Persson, E. S. M.; Grove, D. M.; Bäckvall, J .-E.; van Koten, G. Tetrahedron Lett. 1994, 35, 5931. (f) Persson, E. S. M.; van Klaveren, M.; Grove, D. M.; Bäckvall, J .-E.; van Koten, G. Eur. J . Chem. 1995, 1, 351.

(9) Rijnberg, E.; J astrzebski, J . T. B. H.; J anssen, M. D.; Boersma, J .; van Koten, G. Tetrahedron Lett. 1994, 35, 6521. 569.

(10) van Koten, G.; J astrzebski, J. T. B. H. Tetrahedron 1989, 45 ,
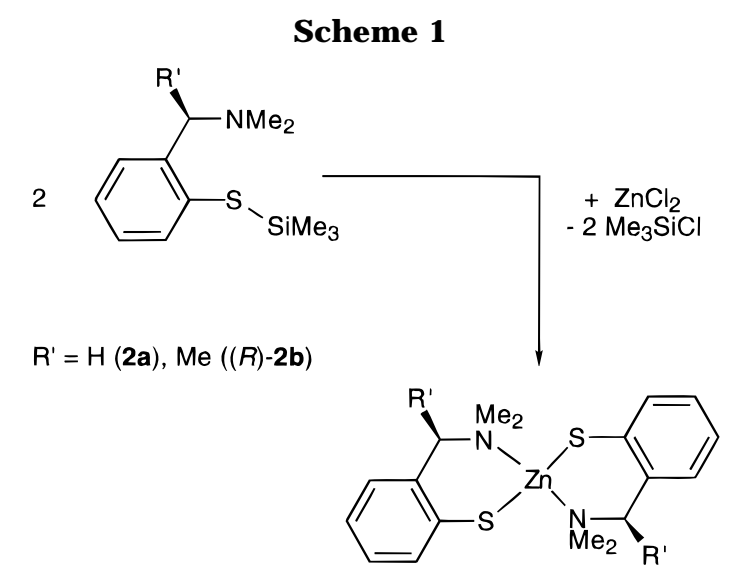

$\mathrm{R}^{\prime}=\mathrm{H}(\mathbf{3} \mathbf{a}), \mathrm{Me}((R, R)-\mathbf{3 b})$

thiolate complexes $\left[(\mathrm{R})-\mathrm{Li}\left(\mathrm{SC}_{6} \mathrm{H}_{4} \mathrm{CH}\left(\mathrm{R}^{\prime}\right) \mathrm{NR}^{\prime \prime}{ }_{2}-2\right)\right]_{6}{ }^{11,12 \mathrm{a}}$ These in situ prepared lithium aminoarenethiolates were subsequently converted into their trimethylsilyl derivatives (R)- $\mathrm{Me}_{3} \mathrm{SiSC}_{6} \mathrm{H}_{4} \mathrm{CH}\left(\mathrm{R}^{\prime}\right) \mathrm{NR}^{\prime \prime}{ }_{2}-2$ ((R)-2) by quenching with $\mathrm{SiMe}_{3} \mathrm{Cl}$. ${ }^{11 b}$ The reaction of $\mathrm{ZnCl}_{2}$ with 2 equiv of $\mathbf{2 a}$ or (R)-2b in $\mathrm{CH}_{2} \mathrm{Cl}_{2}$ or $\mathrm{C}_{6} \mathrm{H}_{6}$ then afforded the monomeric zinc bis(ami noarenethiolate) complexes $\mathrm{Zn}\left(\mathrm{SC}_{6} \mathrm{H}_{4} \mathrm{CH}\left(\mathrm{R}^{\prime}\right) \mathrm{NMe}_{2}-2\right)_{2}(\mathrm{R}=\mathrm{H}(\mathbf{3 a})$, Me $((\mathrm{R}, \mathrm{R})-3 \mathbf{b}))$ as air-stable colorless solids in quantitative yields (Scheme 1). Surprisingly, it proved to be impossible to prepare the pyrrolidinyl and piperidinyl derivatives $(R, R)-3 c$ and $(R, R)-3 d$ via this procedure. These catalyst precursors were applied as free thiols (vide infra).

Cryoscopy in $\mathrm{C}_{6} \mathrm{H}_{6}$ revealed that $(\mathrm{R}, \mathrm{R})-3 \mathrm{~b}$ is monomeric in solution. Unfortunately, the insufficient solubility of $3 a$ in $\mathrm{C}_{6} \mathrm{H}_{6}$ prevented the determination of its aggregation state.

The ${ }^{1} \mathrm{H}$ NMR spectrum of $3 \mathrm{a}$ in $\mathrm{CDCl}_{3}$ at $291 \mathrm{~K}$ shows one $A B$ pattern for the $\mathrm{CH}_{2} \mathrm{~N}$ methylene hydrogen atoms and two distinct singlets for the $\mathrm{NMe}_{2}$ methyl groups, indicating that $\mathrm{Zn}-\mathrm{N}$ coordination is stable and is inert on the NMR time scale. At $321 \mathrm{~K}$ these signals coalesce, indicating that inversion of the configuration of the tetrahedral zinc atom becomes fast on the NMR time scale, most likely as a result of a $\mathrm{Zn}-\mathrm{N}$ dissociation/association process $\left(\Delta \mathrm{G}^{\ddagger}=63.5 \mathrm{~kJ} . \mathrm{mol}^{-1}\right)$. This renders each of the two prochiral groups in the $\mathrm{CH}_{2-}$ $\mathrm{NMe}_{2}$ substituents diastereotopic.

In the temperature range of $364-340 \mathrm{~K}$, the ${ }^{1} \mathrm{H} N \mathrm{NMR}$ spectra of $(R, R)-3 b$ in toluene-d $d_{8}$ show one sharp resonance pattern. When the solution is cooled, the singl et resonance for the $\mathrm{NMe}_{2}$ methyl groups becomes broad and starts to decoalesce at $340 \mathrm{~K}$ into two distinct singlets, indicating that $\mathrm{Zn}-\mathrm{N}$ coordination is becoming stable on the NMR time scale. At $278 \mathrm{~K}$ a broad resonance pattern of a second species becomes visible in the ${ }^{1} \mathrm{H}$ NMR spectrum; this pattern becomes sharp

(11) (a) Knotter, D. M.; van Maanen, H. L.; Grove, D. M.; Spek, A L.; van Koten, G. Inorg. Chem. 1991, 30, 3309. (b) Knotter, D. M.; J anssen, M. D.; Grove, D. M.; Smeets, W. J .J .; Horn, E.; Spek, A. L.; van Koten, G. Inorg. Chem. 1991, 30, 4361.

(12) (a) J anssen, M. D.; Rijnberg, E.; de Wolf, C. A.; Hogerheide, M. P.; Kruis, D.; Spek, A. L.; Grove, D. M.; van Koten, G. Inorg. Chem. 1996, 35, 6735. (b) J anssen, M. D.; Donkervoort, J. G.; van Berlekom S. B.; Spek, A. L.; Grove, D. M.; van Koten, G. Inorg. Chem. 1996, 35 , 4752. (c) Large variations in the $C-S-M$ and $M-S-M$ angles have been found for metal aminoarenethiolate complexes depending on the nature of both the metal cation and the intramolecular coordination. For example, in [CuMes] $4\left[\mathrm{Mg}\left(\mathrm{SC}_{6} \mathrm{H}_{4} \mathrm{CH}_{2} \mathrm{NMe}_{2}-2\right)_{2}\right]_{2}$ the $\mathrm{C}-\mathrm{S}-\mathrm{Mg}$ angle amounts to $89.7(3)^{\circ}$ : Knotter, D. M.; Smeets, W. J.J .; Spek, A. L.; van Koten, G. J . Am. Chem. Soc. 1990, 112, 5895. See also reference $8 b$. 


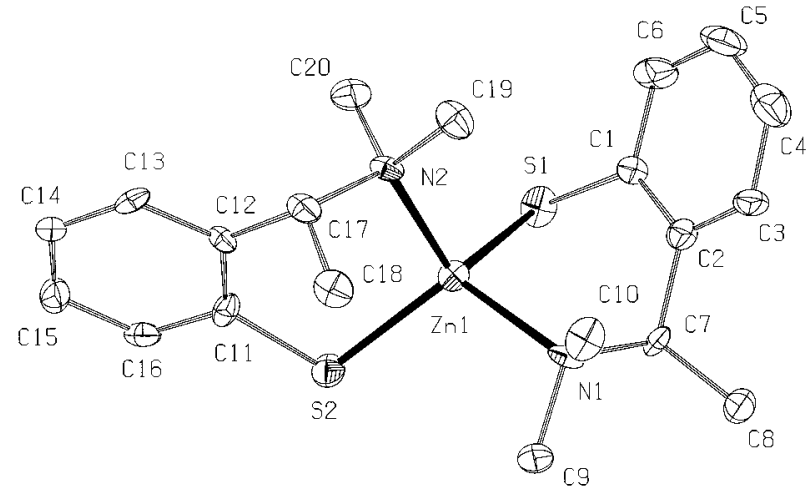

Figure 2. Thermal motion ellipsoid plot (ORTEP) at the $50 \%$ probability level of the molecular structure of $(R, R)-$ 3b. Hydrogen atoms have been omitted for clarity.

Table 1. Selected Bond Distances, Bond Angles, and Dihedral Angles for $(R, R)-3 b^{a}$

\begin{tabular}{cccc}
\hline \multicolumn{5}{c}{ Bond Distances $(\AA)$} \\
$\mathrm{Zn}(1)-\mathrm{S}(1)$ & $2.284(3)$ & $\mathrm{Zn}(1)-\mathrm{N}(1)$ & $2.146(8)$ \\
$\mathrm{Zn}(1)-\mathrm{S}(2)$ & $2.260(2)$ & $\mathrm{Zn}(1)-\mathrm{N}(2)$ & $2.096(6)$ \\
$\mathrm{S}(1)-\mathrm{C}(1)$ & $1.76(1)$ & $\mathrm{S}(2)-\mathrm{C}(11)$ & $1.753(9)$ \\
\multicolumn{5}{c}{ Bond Angles (deg) } \\
$\mathrm{S}(1)-\mathrm{Zn}(1)-\mathrm{N}(1)$ & $99.7(2)$ & $\mathrm{S}(1)-\mathrm{Zn}(1)-\mathrm{S}(2)$ & $119.64(10)$ \\
$\mathrm{S}(2)-\mathrm{Zn}(1)-\mathrm{N}(2)$ & $101.3(2)$ & $\mathrm{N}(1)-\mathrm{Zn}(1)-\mathrm{N}(2)$ & $117.9(3)$ \\
$\mathrm{Zn}(1)-\mathrm{S}(1)-\mathrm{C}(1)$ & $93.8(3)$ & $\mathrm{Zn}(1)-\mathrm{S}(2)-\mathrm{C}(11)$ & $106.5(3)$ \\
\multicolumn{5}{c}{ Dihedral } & Angles (deg) \\
$\mathrm{C}(3)-\mathrm{C}(2)-$ & $-29.7(12)$ & $\mathrm{C}(13)-\mathrm{C}(12)-$ & $107.1(8)$ \\
$\mathrm{C}(7)-\mathrm{C}(8)$ & \multicolumn{5}{c}{$\mathrm{C}(17)-\mathrm{C}(18)$} \\
\end{tabular}

a The estimated standard deviations are given in parentheses.

at $254 \mathrm{~K}$. The two species are present in an approximately 5:2 molar ratio. The minor species shows four distinct singlets for the $\mathrm{NMe}_{2}$ methyl groups and two quartets for the benzylic hydrogen atoms. Upon further cooling of the solution to below $254 \mathrm{~K}$ a third minor resonance pattern becomes visible in the ${ }^{1} \mathrm{H}$ NMR spectrum. The latter species also shows four distinct singlets for the $\mathrm{NMe}_{2}$ methyl groups, but the two accompanying quartets are most likely hidden under other signals. The NMR data suggest that of the six possible isomers of $(R, R)-3 b$ (videinfra) three are visible in the NMR.

To determine the molecular structure of optically pure $(R, R)-3 b$ in the solid state, a single-crystal X-ray diffraction study was carried out. A thermal motion ellipsoid plot of the molecular structure of $(R, R)-3 \mathbf{b}$ together with the adopted numbering scheme is shown in Figure 2 with bond distances and bond angles being given in Table 1.

In the solid state $(\mathrm{R}, \mathrm{R})$-3b is a monomer that consists of a zinc atom carrying two monoanionic, S,N-chelatebonded 2-[1-(dimethylamino)ethyl]thiophenolate ligands. The four-coordinate zinc atom has a distorted-tetrahedral geometry, which is apparent from the $S-Z n-N$ bite angles of $99.7(2)$ and $101.3(2)^{\circ}$. The $\mathrm{Zn}-\mathrm{S}$ bond lengths of 2.284(3) and 2.260(3) $\AA$ are comparable to those reported for the related complexes $\mathrm{Zn}\left[\mathrm{S}\left(\mathrm{CH}_{2}\right)_{2} \mathrm{NMe}_{2}\right]_{2}$ and $\mathrm{Zn}\left(\mathrm{SCMe}_{2} \mathrm{CH}_{2} \mathrm{NH}_{2}\right)_{2}$, where they are in the range of 2.253-2.295 $\AA .13$ The angles $\mathrm{Zn}(1)-\mathrm{S}(1)-\mathrm{C}(1)$ and $\mathrm{Zn}(1)-\mathrm{S}(2)-\mathrm{C}(11)$ of $93.8(4)$ and $106.5(3)^{\circ}$ indicate a distorted-tetrahedral geometry of the sulfur atoms. The $\mathrm{Zn}-\mathrm{N}$ bond lengths of 2.096(6) and 2.146(8) $\AA$ are

(13) (a) Cohen, B.; Mastropaolo, D.; Potenza, J. A.; Schugar, H. J . Acta Crystallogr. 1978, B34, 2859. (b) Casals, I.; Gonzalez-Duarte, P.; Lopez, C.; Solans, X. Polyhedron 1990, 9, 763. significantly shorter than those in four-coordinate diorganozinc compounds such as $\left.\mathrm{Zn}\left[\left(\mathrm{CH}_{2}\right)_{3} \mathrm{NMe}\right)_{2}\right]_{2}(\mathbf{1 3}),{ }^{14 a}$ $\mathrm{ZnMe}_{2}$ (tmeda) (14), ${ }^{14 \mathrm{~b}}$ and $\mathrm{Zn}\left(\mathrm{CH}_{2} \mathrm{CMe}_{3}\right)_{2}$ (tmeda) (15) (tmeda $\left.=\mathrm{Me}_{2} \mathrm{~N}\left(\mathrm{CH}_{2}\right)_{2} \mathrm{NMe}_{2}\right),(2.260(8)-2.411(4) \AA)$. The intramolecular $\mathrm{Zn}-\mathrm{N}$ coordination gives rise to the formation of two six-membered chelate rings, which have different puckering, as is evident from the different dihedral angles between the $\alpha$-methyl groups and the planes of the adjacent aryl rings, i.e. $-29.7(12)$ and $107.1(8)^{\circ}$ for $\mathrm{C}(3)-\mathrm{C}(2)-\mathrm{C}(7)-\mathrm{C}(8)$ and $\mathrm{C}(13)-\mathrm{C}(12)-$ $C(17)-C(18)$, respectively.

Organozinc Aminoarenethiolates. The zinc bis(aminoarenethiolates) $\mathbf{3 a}$ and $(\mathrm{R}, \mathrm{R})$-3b react with diorganozinc compounds via a comproportionation reaction to afford instantaneously the corresponding organozinc aminoarenethiolates (R)-RZn( $\left.\mathrm{SC}_{6} \mathrm{H}_{4} \mathrm{CHR}^{\prime} \mathrm{NMe}_{2}-2\right)\left(\mathrm{R}, \mathrm{R}^{\prime}\right.$ $=\mathrm{Me}, \mathrm{H}$ (4a-Me), Et, H (4a-Et), Me, Me ((R)-4b-Me), $\mathrm{Et}$, Me ((R)-4b-Et)) in nearly quantitative yields. Another route to these complexes, which also gives access to the organozinc aminoarenethiolates (R)-MeZn $\left(\mathrm{SC}_{6} \mathrm{H}_{4}\right.$ CHMeNR" $\left.{ }_{2}-2\right)\left(\mathrm{R}^{\prime \prime}=\left(\mathrm{CH}_{2}\right)_{4}((\mathrm{R})-\mathbf{4 c}-\mathrm{Me}),\left(\mathrm{CH}_{2}\right)_{5}((\mathrm{R})-\right.$

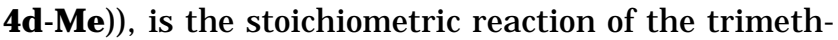
ylsilyl aminoarenethiolates $\mathbf{2}$ with the appropriate (in situ prepared) organozinc halide, see Scheme 2.11b Alternatively, (R)-4c-Me and (R)-4d-Me are prepared by reacting a slight excess of $\mathrm{ZnMe}_{2}$ with the aminothiophenols (R)-HSC $\left.{ }_{6} \mathrm{H}_{4} \mathrm{CHMeNR}_{2}-2\right)((\mathrm{R})-\mathbf{1 c}$ and (R)-1d). The latter were obtained via hydrolysis of the in situ prepared lithium aminoarenethiolates with $30 \%$ aqueous $\mathrm{HCl}$.11a

The ${ }^{1} \mathrm{H}$ NMR spectra of $\mathbf{4 a -} \mathbf{R}$ and (R)-4b-R $(\mathbf{R}=\mathrm{Me}$, $\mathrm{Et}$ ) at el evated temperatures show one sharp resonance pattern for the equivalent $\mathrm{NMe}_{2}$ methyl groups in addition to the resonances of the methyl or ethyl group bonded to zinc. The integral ratios indicate that the aminoarenethiolate ligand and the organic group bonded to zinc are present in a 1:1 ratio. Decoal escence of the singlet resonances for the $\mathrm{NMe}_{2}$ methyl groups starts at 254 and $266 \mathrm{~K}$ for $\mathbf{4 a - R}$ and (R)-4b-R ( $\mathbf{R}=\mathrm{Me}, \mathrm{Et})$, respectively. The broad signals and the complicated overlapping of many of the resonance patterns in the ${ }^{1} \mathrm{H}$ NMR spectra at low temperatures precluded assignments.

The ${ }^{1} \mathrm{H}$ NMR spectra of (R)-4c-Me and (R)-4d-Me in toluene- $\mathrm{d}_{8}$ over the temperature range $364-303 \mathrm{~K}$ also show one sharp resonance pattern. Upon cooling of the solutions the signals of the zinc-bonded methyl groups, the aryl protons in the ortho position, and the benzylic hydrogen atoms become broad and start to decoalesce at $293 \mathrm{~K}$. U pon further cooling of the solution to $193 \mathrm{~K}$ the ${ }^{1} \mathrm{H}$ NMR spectra of both compounds show one sharp unsymmetrical resonance pattern, consisting of two doublets for the aryl protons in the ortho position, two

(14) (a) Dekker, J .; Boersma, J .; Fernholt, L.; Haaland, A.; Spek, A L.Organometallics 1987, 6, 1202. (b) O'Brien, P.; Hursthouse, M. B. Motevalli, M.; Walsh, J. R.; J ones, A. C. J . Organomet. Chem. 1993, 449, 1.

(15) In a separate experiment we found under the applied reaction conditions a conversion of benzaldehyde and $\mathrm{PhCH}_{2} \mathrm{CH}_{2} \mathrm{CHO}$ with commercially available $\mathrm{ZnEt}_{2}$ without the addition of a catalyst into the corresponding (racemic) secondary alcohols of 13 and $40 \%$, respectively. The observed reactivity is as yet an unsettled question, since many reports refer to the statement that aldehydes are inert toward $\mathrm{ZnEt}_{2}$. Boersma, J. In Comprehensive Organometallic Chemistry Wilkinson, G.; Stone, F. G. A.; Abel, E. W. (Eds.): Pergamon: New York, 1982; Vol. 2, p 823.

(16) (a) Yamakawa, M.; Noyori, R. M. J . Am. Chem. Soc. 1995, 117, 6327. (b) Kitamura, M.; Yamakawa, M.; Oka, H.; Suga, S.; Noyori, R. Chem. Eur. J . 1996, 2, 1173. 


\section{Scheme 2}

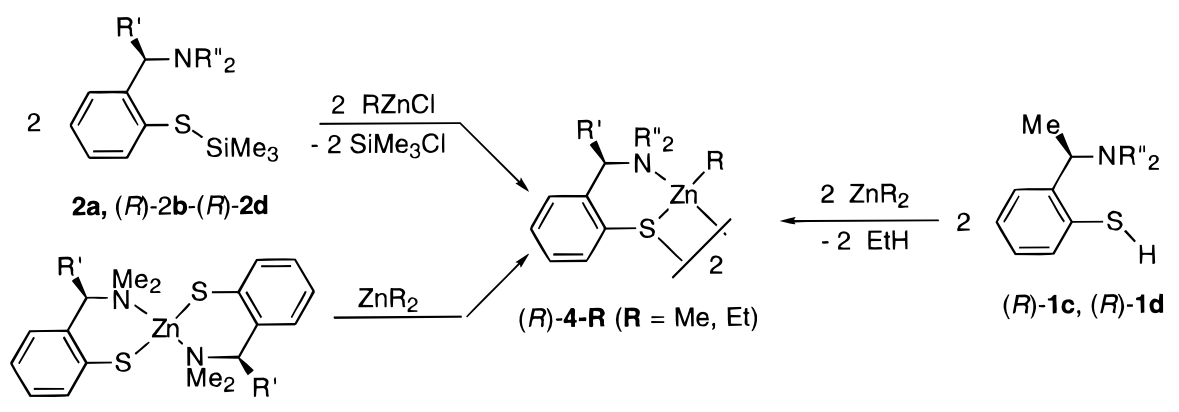

3a, $(R, R)-\mathbf{3 b}$

Table 2. Addition of $\mathrm{ZnEt}_{2}$ to Benzaldehyde in the Presence of Various Catalysts in Toluene

\begin{tabular}{clccc}
\hline $\begin{array}{c}\text { entry } \\
\text { no. }\end{array}$ & catalyst & $\begin{array}{c}\text { amt of } \\
\text { catalyst } \\
\text { (mol \%) }\end{array}$ & $\begin{array}{c}\text { yield of } \mathbf{5 b} \\
(\%)^{\mathrm{a}}\end{array}$ & $\begin{array}{c}\text { ee of (S)-5b } \\
(\%)^{b}\end{array}$ \\
\hline 1 & none & & $13^{\mathrm{c}}$ & 0 \\
2 & 3a & 2 & 94 & 0 \\
3 & (R,R)-3b & 2 & 99 & 94 \\
4 & (R)-4b-Et & 4 & $>99$ & 92 \\
5 & (R)-1c & 4 & 93 & 98 \\
6 & (R)-1d & 4 & $>99$ & 96
\end{tabular}

a GC yield, defined by conversion times selectivity. ${ }^{b}$ Enantiomeric excess determined by HPLC using a Diacel Chiralcel OD column. Absolute configurations were determined from optical rotation. ' Reference 15.

quartets for the benzylic hydrogen atoms and two singlets for the zinc-bonded methyl groups.

Catalytic 1,2-Addition Reactions. Both the zinc bis(aminoarenethiolates) $\mathbf{3 a}$ and $(\mathrm{R}, \mathrm{R})-\mathbf{3 b}$ and the aminothiophenols ( $R$ )-1c and (R)-1d were tested in catalytic 1,2-additions of diethylzinc to benzal dehyde. We found that the presence of a catalytic amount of either a zinc bis(aminoarenethiolate) or an aminothiophenol significantly enhances the rate of the reaction between diethylzinc and benzaldehyde to give 1-phenyl-1-propanol (5b) nearly quantitatively after hydrolysis. Moreover, the reactions in which optically pure chiral aminoarenethiolate ligands were used proceeded with excellent enantioselectivities. The use of separately prepared (R)4b-Et, which itself is inert toward benzaldehyde, gave a result identical with that obtained with the parent zinc bis(aminoarenethiolate) $(R, R)-\mathbf{3 b}$. The best results are obtained with (R)-1d having a N $\left(\mathrm{CH}_{2}\right)_{5}$ substituent (see Table 2). The use of the pyrrolidinyl and piperidinyl thiols (R)-1c and (R)-1d as precursor catalysts not only leads to optimal chemo- and enantioselectivities but also gives by far the fastest rate in the conversion of benzaldehyde into (S)-1-phenyl-1-propanol ((S)-5b) (see Figure 3).

$$
\stackrel{\text { 1. } \mathrm{ZnEt}_{2} / \text { catalyst }}{\stackrel{2 . \mathrm{H}_{2} \mathrm{O}}{\text { toluene; } \mathrm{rt}}}
$$

(S)-5b

To determine the scope of the present catalysts, 1,2addition reactions of various aromatic and aliphatic aldehydes with di ethylzinc were carried out. It appears that the amount of chiral induction clearly depends on the nature of the aldehyde: whereas $\alpha, \beta$-unsaturated and aliphatic aldehydes afford the corresponding alcohols (S)-10 and (S)-12 with only moderate ee's of 75\%

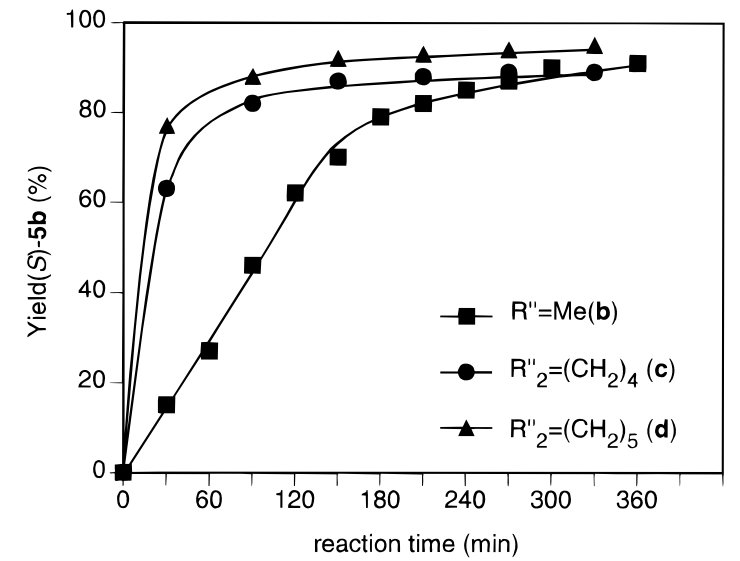

Figure 3. Comparison of the reaction rates of the reaction of benzaldehyde with $\mathrm{ZnEt}_{2}$ catalyzed by $(\mathrm{R}, \mathrm{R})-\mathbf{3 b},(\mathrm{R})-\mathbf{1 c}$, and (R)-1d.

Table 3. Aminoarenethiolate-Catalyzed Addition of Diethylzinc to Various Aldehydes in Toluene

\begin{tabular}{cllccrc}
\hline $\begin{array}{c}\text { entry } \\
\text { no. }\end{array}$ & \multicolumn{1}{c}{$\mathrm{R}^{1}$} & catalyst & $\begin{array}{c}\text { amt of } \\
\text { catalyst } \\
(\text { mol \%) }\end{array}$ & product & $\begin{array}{c}\text { yield } \\
(\%)^{\mathrm{a}}\end{array}$ & $\begin{array}{c}\text { ee } \\
(\%)^{\mathrm{b}}\end{array}$ \\
\hline 1 & $2-\mathrm{ClC}_{6} \mathrm{H}_{4}$ & (R,R)-3b & 2 & $\mathbf{6}$ & 96 & $92(\mathrm{~S})$ \\
2 & $4-\mathrm{ClC}_{6} \mathrm{H}_{4}$ & (R,R)-3b & 2 & $\mathbf{7}$ & 99 & $97(\mathrm{~S})$ \\
3 & $4-\mathrm{MeOC}_{6} \mathrm{H}_{4}$ & (R,R)-3b & 2 & $\mathbf{8}$ & 94 & $95(\mathrm{~S})$ \\
4 & $4-\mathrm{MeC}_{6} \mathrm{H}_{4}$ & (R,R)-3b & 2 & $\mathbf{9}$ & $>99$ & $99(\mathrm{~S})$ \\
5 & $(\mathrm{E})-\mathrm{C}_{6} \mathrm{H}_{5} \mathrm{CH}=\mathrm{CH}$ & (R,R)-3b & 2 & $\mathbf{1 0}$ & 95 & $75(\mathrm{~S})$ \\
6 & $2-\mathrm{furyl}_{7}$ & (R,R)-3b & 2 & $\mathbf{1 1}$ & $>99$ & $89(\mathrm{~S})$ \\
7 & $\mathrm{C}_{6} \mathrm{H}_{5} \mathrm{CH}_{2} \mathrm{CH}_{2}$ & (R,R)-3b & 2 & $\mathbf{1 2}$ & 98 & $69(\mathrm{~S})$ \\
8 & $\mathrm{C}_{6} \mathrm{H}_{5} \mathrm{CH}_{2} \mathrm{CH}_{2}$ & (R)-1c & 4 & $\mathbf{1 2}$ & $>99$ & $80(\mathrm{~S})$ \\
9 & $\mathrm{C}_{6} \mathrm{H}_{5} \mathrm{CH}_{2} \mathrm{CH}_{2}$ & (R)-1d & 4 & $\mathbf{1 2}$ & $>99$ & $82(\mathrm{~S})$
\end{tabular}

a $\mathrm{GC}$ yield, defined by conversion times selectivity. ${ }^{\mathrm{b}}$ The enantiomeric excess was determined by HPLC using a Diacel Chiralcel OD column unless stated otherwise. Absolute configurations were determined from optical rotation. ${ }^{c}$ The enantiomeric excess was determined by ${ }^{1} \mathrm{H}$ NMR using the chiral shift reagent $\mathrm{Eu}(\mathrm{tfc}) 3$.

and $69 \%$ (Table 3, entries 5 and 7), the aromatic al dehydes gave the al cohols (S)-5b-(S)-9 with excellent ee's of $\geq 94 \%$.

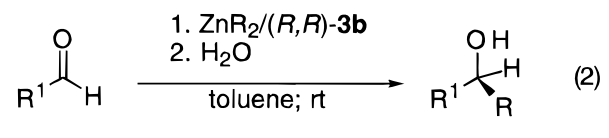

$(S)-5 a-(S)-12 c$

A striking difference in reactivity of the aminoarenethiolate ligands toward benzal dehyde was found upon the application of other diorganozinc compounds, i.e commercially available dimethylzinc and separately prepared diisopropylzinc. Excellent results are obtained with dimethylzinc, although this reaction is much slower than that of diethylzinc. The reaction of diisopropylzinc with benzaldehyde gave significant amounts 
Table 4. Comparison of the Catalyst Selectivities in the 1,2-Addition of Diorganozinc Compounds to Benzaldehyde in Toluene

\begin{tabular}{cccccccc}
\hline $\begin{array}{c}\text { entry } \\
\text { no. }\end{array}$ & $\mathrm{R}^{1}$ & $\mathrm{R}$ & catalyst & $\begin{array}{c}\text { amt of } \\
\text { catalyst } \\
\text { (mol \%) }\end{array}$ & product & $\begin{array}{c}\text { yield } \\
(\%)^{\mathrm{a}}\end{array}$ & ee (\%) \\
\hline 1 & $\mathrm{Ph}$ & $\mathrm{Me}$ & (R,R)-3b & 2 & $\mathbf{5 a}$ & $88^{\mathrm{c}}$ & $94(\mathrm{~S})$ \\
3 & $\mathrm{Ph}$ & $\mathrm{Me}$ & (R)-1d & 4 & $\mathbf{5 a}$ & $97^{\mathrm{c}}$ & $93(\mathrm{~S})$ \\
2 & $\mathrm{Ph}$ & $\mathrm{Et}$ & (R,R)-3b & 2 & $\mathbf{5 b}$ & 99 & $94(\mathrm{~S})$ \\
4 & $\mathrm{Ph}$ & $\mathrm{Et}$ & (R)-1d & 4 & $\mathbf{5 b}$ & $>99$ & $96(\mathrm{~S})$ \\
5 & $\mathrm{Ph}$ & $\mathrm{i}-\mathrm{Pr}$ & (R,R)-3b & 2 & $\mathbf{5 c}$ & 45 & $80(\mathrm{~S})$ \\
6 & $\mathrm{Ph}$ & $\mathrm{i}-\mathrm{Pr}$ & (R)-1d & 4 & $\mathbf{5 c}$ & 68 & $91(\mathrm{~S})$
\end{tabular}

a GC yield, defined by conversion times selectivity. ${ }^{b}$ Enantiomeric excess determined by HPLC using a Diacel chiralcel OD column. Absolute configurations were determined from optical rotation. ${ }^{\mathrm{C}}$ Conversion after $68 \mathrm{~h}$.

Table 5. Addition of Diethylzinc to Benzaldehyde with $2 \mathrm{~mol} \%$ of $(R, R)-3 b$ Catalyst in Toluene: Influence of the Presence of Various Cosolvents

\begin{tabular}{clcc}
\hline $\begin{array}{c}\text { entry } \\
\text { no. }\end{array}$ & cosolvent & $\begin{array}{c}\text { yield of } \mathbf{5 b} \\
(\%)^{\mathrm{a}}\end{array}$ & $\begin{array}{c}\text { ee of (S)-5b } \\
(\%)^{\mathrm{b}}\end{array}$ \\
\hline 1 & & 99 & 94 \\
2 & t-BuOMe & 85 & 89 \\
3 & $\mathrm{Et}_{2} \mathrm{O}$ & 89 & 83 \\
4 & thf & 9 & 74
\end{tabular}

${ }^{a} \mathrm{GC}$ yield, defined by conversion times selectivity. ${ }^{\mathrm{b}}$ Enantiomeric excess determined by HPLC using a Diacel Chiralcel OD column. Absolute configurations were determined from optical rotation.

of benzyl alcohol and 2-methyl-1-phenyl-1-propanone as side products. As is obvious from the data in Table 4, the application of $(R)-\mathbf{l d}$ as the precursor catalyst significantly improves the results of the reaction between benzaldehyde and diisopropylzinc as well as the yield of 1-phenyl-1-ethanol ((S)-5a) in the reaction with dimethylzinc.

There is a significant effect of the solvent on the outcome of the 1,2-additions of benzaldehyde with diethylzinc catalyzed by (R,R)-3b (see Table 5 ). In toluene and in the presence of t-BuOMe, the conversions of benzal dehyde after $17 \mathrm{~h}$ were $>99$ and $92 \%$, respectively. However, in the presence of a large excess of thf the reaction proceeds very slowly, and low chemo- and enantioselectivities are obtained.

To get insight into the mechanism of these 1,2additions, the effect of the optical purity of the catalyst precursor $(R, R)-3 b$ on the selectivity was investigated. As shown in Figure 4, the ee of the product (S)-5b has a nonlinear relation with the ee of the catalyst precursor $(R, R)-3 b$. This nonlinear effect is positive in the range for $0-100 \%$ ee of $(R, R)-3 b$. The optical purity also considerably affects the reactivity: the use of $(R, R)-\mathbf{3 b}$ with an ee of $100 \%$ gives complete conversion of benzaldehyde to (S)-5b after $17 \mathrm{~h}$, whereas the use of $20 \%$ ee $(R, R)-3 b$ gives a lower conversion ( $83 \%$ of $(S)-5 b$ ) under identical reaction conditions.

According to the results presented in Tables 3 and 4, the alkylation reactions of al dehydes in the presence of either optically pure zinc bis(aminoarenethiolate) $(R, R)$ $\mathbf{3 b}$ or one of the aminoarenethiols (R)-1d or (R)-1d, all having the $\mathrm{R}$ configuration at the stereogenic benzylic carbon center, produce (after hydrolysis) the corresponding optically active S secondary alcohols. Accordingly, it can be concluded that the transfer of the stereochemical information from the catalyst to the product fol lows the configurational rules formulated by Noyori et al. for similar reactions catalyzed by chiral aminoal koxide ligands. ${ }^{3 a}$

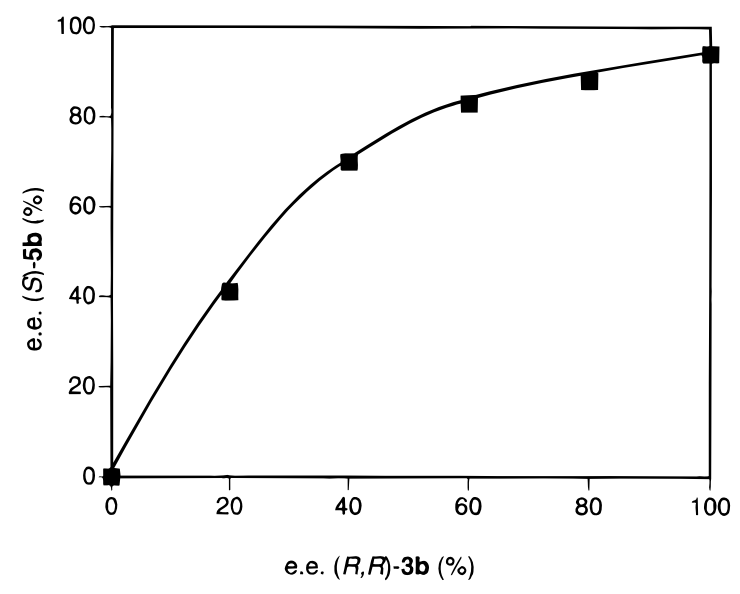

Figure 4. Relation between the ee of product (S)-5b and that of the catalyst $(R, R)-3 b$ ( $100 \%$ de; vide infra) in the $(R, R)$-3b-catalyzed reaction of benzal dehyde and $Z n E t_{2}$.

\section{Discussion}

The (Precursor) Catalysts. In practice, the catalyst in the 1,2-addition reaction of diorganozinc compounds to aldehydes is prepared in situ by protonolysis of 1 equiv of $Z n R_{2}$ by the amino alcohol to give an organozinc alkoxide. We have used this approach for the in situ synthesis of the organozinc aminoarenethiolate catalysts, but we have also developed an alternative route by reacting a zinc bis(aminoarenethiolate) with a diorganozinc compound (comproportionation). These zinc bis(aminoarenethiolates) can be isolated as air-stable odorless materials, which is an advantage over the aminothiophenols. An additional advantage of these precursor catalysts is that they are available in both enantiomeric forms in high yields from the cheap, optically pure (S)- or (R)-(1-phenylethyl)amines.

The $(R, R)$-3b we used was prepared from (R)-(1phenylethyl)amine with an optical purity of $96 \%$. Therefore, three diastereoisomeric complexes could have been formed, (R, R)-3b, $(R, S)-3 \mathbf{b}$, and $(S, S)-\mathbf{3 b}$, in a statistical 96.04:3.92:0.04 distribution. Consequently, uncrystallized $(R, R)-3 b$ is calculated to have an ee of $99.9 \%$ and a de of $92 \%$. Therefore, the NMR experiments were performed with recrystallized material.

The ${ }^{1} \mathrm{H}$ NMR spectra of $\mathbf{3 a}$ and $(R, R)-3 b$ reveal that the overall molecular structure of $(R, R)-\mathbf{3 b}$ in the solid state is also present in solution at temperatures below $278 \mathrm{~K}$ : the presence of intramolecular $\mathrm{Zn}-\mathrm{N}$ coordination in $\mathbf{3 a}$ and $(\mathrm{R}, \mathrm{R})-\mathbf{3 b}$ in solution is supported by the diastereotopicity of the $\mathrm{CH}_{2} \mathrm{~N}$ methylene hydrogen atoms and the $\mathrm{NMe}_{2}$ methyl groups. Since the $\mathrm{Zn}-\mathrm{N}$ coordination is becoming stable on the NMR time scale at $340 \mathrm{~K}$, the zinc atom in $(R, R)-3 b$ represents a stereogenic tetrahedral center and exists in either the $Z n_{(R)}$ or the $Z n_{(S)}$ configuration, resulting in two dia-

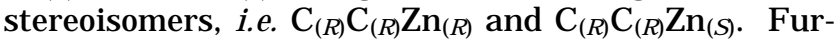
thermore, each diastereoi somer contains two puckered six-membered chelate rings, which both can have either the $\delta$ or the $\lambda$ conformation. Theoretically six isomers of $(R, R)-3 b$ are expected, four of which are shown in Figure 5. In A, B, D, and E both six-membered chelate rings have identical puckering; however, the positions of the $\alpha$-methyl groups are different. In $\mathbf{A}$ and $\mathbf{D}$ both $\alpha$-methyl groups occupy the favored axial positions, i.e. approximately perpendicular (antiplanar) to the adjacent aryl ring, whereas in $\mathbf{B}$ and $\mathbf{E}$ both $\alpha$-methyl groups 


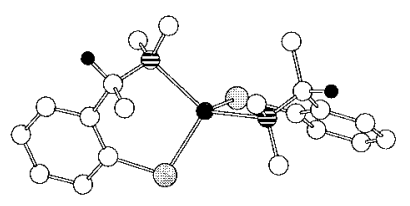

A

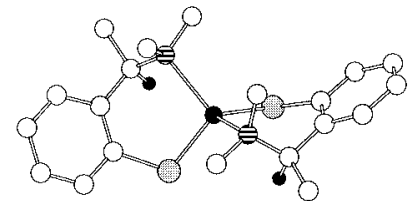

B

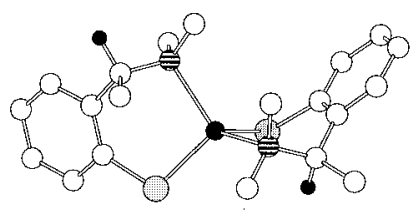

C

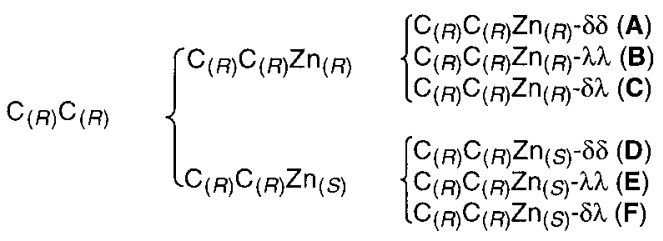

diastereoisomers conformers

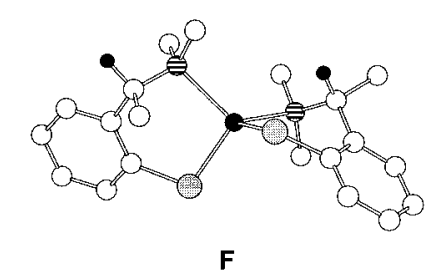

Figure 5. Selected diastereoisomeric and conformeric structures of $(R, R)-3 b$.<smiles>O=[N+]1CCC[Te]12CCCN2O</smiles>

13

$2.307(4) \AA$

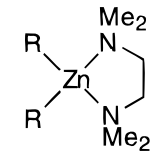

$$
\begin{array}{cc}
14 & 15 \\
R=M e & R=\mathrm{CH}_{2} \mathrm{CMe}_{3} \\
2.260(8) \AA & 2.411(4) \AA \\
2.278(8) \AA &
\end{array}
$$

Figure 6. Comparison of the $\mathrm{Zn}-\mathrm{N}$ bond distances in $(R, R)-3 b$ and those in nitrogen-coordinated $Z_{n} R_{2}$ complexes.

are forced in the unfavored equatorial positions, i.e. approximately in-plane (periplanar) with the adjacent aryl ring. In $\mathbf{C}$ and $\mathbf{F}$ the two six-membered chelate rings have opposite puckering, which results in one ring with an antiplanar and one ring with a periplanar $\alpha$-methyl group.

In the case of $\mathbf{A}, \mathbf{B}, \mathbf{D}$, and $\mathbf{E}$ only one resonance pattern is expected for each of the chelate rings, characterized by two singlets for the $\mathrm{NMe}_{2}$ methyl groups and one pattern for the $\mathrm{C}(\mathrm{Me}) \mathrm{H}$ group. Such a pattern is observed for the major species in toluene- $d_{8}$ solutions of $(R, R)-3 b$ at $278 \mathrm{~K}$. F or $\mathbf{C}$ and $\mathbf{F}$ we expect two resonance patterns for each of the chelate rings, characterized by four singlets for the $\mathrm{NMe}_{2}$ methyl groups and two patterns for the $\mathrm{C}(\mathrm{Me}) \mathrm{H}$ group. Two such resonance patterns are observed for the minor species in solution at $205 \mathrm{~K}$. In the ${ }^{1} \mathrm{H}$ NMR spectra of $(\mathrm{R}, \mathrm{R})-3 \mathrm{~b}$ in toluene- $\mathrm{d}_{8}$ at temperatures below $254 \mathrm{~K}$, only two other species are observed in addition to one major species. This indicates that three isomers of $(R, R)-3 b$ can be frozen out below $254 \mathrm{~K}$ from the equilibrium between the diastereoisomers and the conformers that is present at elevated temperatures. It must be noted that the molecular geometry of $(R, R)-3 \mathbf{b}$ in the solid state is that of $\mathbf{C}$.

A conspicuous feature of the structure of $(R, R)-3 b$ is the significant shortening of the $\mathrm{Zn}-\mathrm{N}$ bond distances compared with these distances in $\left.\mathrm{Zn}\left[\left(\mathrm{CH}_{2}\right)_{3} \mathrm{NMe}\right)_{2}\right]_{2}$ (13), ${ }^{14 a} \mathrm{ZnMe}_{2}$ (tmeda) (14), and $\mathrm{Zn}\left(\mathrm{CH}_{2} \mathrm{CMe}_{3}\right)_{2}$ (tmeda) (15) (tmeda $\left.=\mathrm{Me}_{2} \mathrm{~N}\left(\mathrm{CH}_{2}\right)_{2} \mathrm{NMe}_{2}\right)$. ${ }^{14 \mathrm{~b}}$ This points to a considerably higher Lewis acidity of the zinc center in $(R, R)-3 b$, i.e. to a larger polarity of the $\mathrm{Zn}$-S bond as compared with the $\mathrm{Zn}-\mathrm{C}$ bond in 13, 14, and $\mathbf{1 5}$.

A consequence of this bond shortening is that vicinal interactions between substituted groups at the zinc center and at the neighboring nitrogen centers are significantly enhanced. This will result in higher energy barriers for rotation around the $\mathrm{Zn}-\mathrm{N}$ bonds, i.e. increased kinetic stability of the different ring conformers. This is corroborated by the observation in the ${ }^{1} \mathrm{H}$ $N M R$ of at least three distinct $(R, R)-3 b$ isomers. A further consequence of the short $\mathrm{Zn}-\mathrm{N}$ bonds is that during catalysis the strong $\mathrm{Zn}-\mathrm{N}$ interaction facilitates an efficient transfer of the stereochemistry from the stereogenic benzylic carbon atom al ong the $\mathrm{C}-\mathrm{N}$ bonds and the $\mathrm{N}-\mathrm{Zn}$ bonds to the zinc center in the actual catalyst (vide infra). Finally, the compact $\mathrm{Zn}-\mathrm{N}-\mathrm{C}$ arrangement will also cause any change of the substituents at these atoms to have considerable effects. This is clearly the case when the $\mathrm{NMe}_{2}$ group in $(\mathrm{R}, \mathrm{R})-\mathbf{3 b}$ is replaced by a $\mathrm{N}\left(\mathrm{CH}_{2}\right)_{4}$ or a $\mathrm{N}\left(\mathrm{CH}_{2}\right)_{5}$ group: as stated before, it was not possible to isolate the last two zinc bis(aminoarenethiolates) (R,R)-3c and (R,R)-3d. The reason for this may be that the enhanced Lewis basicity of the latter amino substituents causes an even stronger $\mathrm{Zn}-\mathrm{N}$ interaction, resulting in an increased steric congestion at the nitrogen center. However, the correspondingly less crowded dimeric alkylzinc aminoarenethiol ates are easily accessible, and (R)-4c-Me and (R)-4d-Me were isolated. In these dimers each zinc center is S,N-chelate bonded to one ami noarenethi olate ligand and a methyl group is present instead of a second bulky $\mathrm{N}\left(\mathrm{CH}_{2}\right)_{4}$ or $\mathrm{N}\left(\mathrm{CH}_{2}\right)_{5}$ substituent. Notably, the ${ }^{1 \mathrm{H}}$ NMR spectra of (R)-4c-Me and (R)-4d-Me at low temperatures show exclusively one species with two resonance patterns for two chelate rings. The structural features of these dimers are obvious from the mol ecular structure of (R)-4b-Me, ${ }^{11 b}$ shown in Figure 7.

The solid-state structure of dimeric $[(\mathrm{R})-\mathbf{4 b}-\mathbf{M e}]_{2}$ shows $\mathrm{Zn}-\mathrm{N}$ bond distances that are comparable to those found for $(R, R)-3 b$, but the $Z n-S$ bond distances of the $\mathrm{S}, \mathrm{N}$-chelated ligands in $[(\mathrm{R})-\mathbf{4 b}-\mathbf{M e}]_{2}$ are significantly el ongated. The two six-membered chelate rings in $[(\mathrm{R})-\mathbf{4 b}-\mathbf{M e}]_{2}$ show different puckering, as illustrated by the dihedral angles between the $\alpha$-methyl groups and the planes of the adjacent aryl rings $(-17.4(8)$ and $107.3(6)^{\circ}$, respectively). This points to enhanced steric interactions between the protons of the periplanar $\alpha$-methyl group and the neighboring aryl proton in [(R)$\mathbf{4 b}-\mathbf{M e}]_{2}$ when compared to $(R, R)-3 \mathbf{b}$.

The central $\mathrm{Zn}_{2} \mathrm{~S}_{2}$ core in $[(\mathrm{R})-\mathbf{4 b}-\mathbf{M e}]_{2}$ is planar within experimental error. The acute $\mathrm{Zn}-\mathrm{S}-\mathrm{Zn}$ angl es of about $80^{\circ}$ suggest that the sulfur atoms are bonded to two zinc atoms by electron-deficient two-electron- 


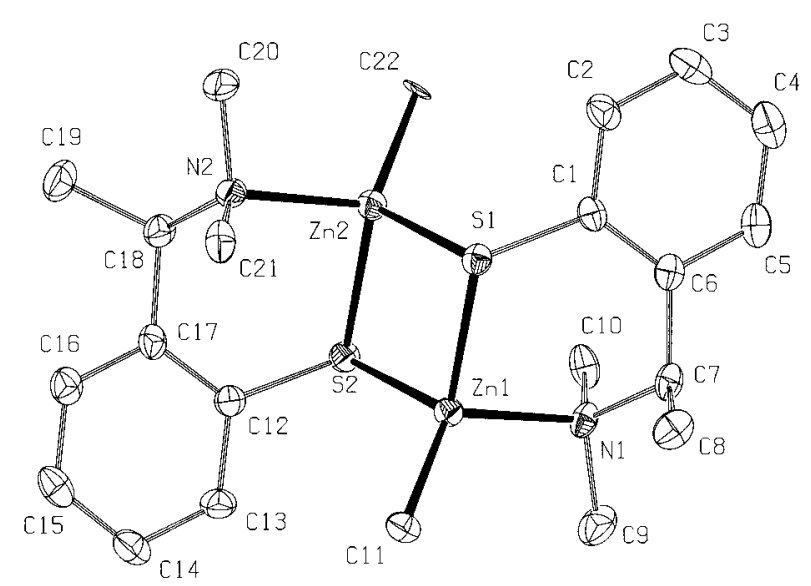

Figure 7. Thermal motion ellipsoid plot (ORTEP) at the $50 \%$ probability level of the molecular structure of $[(\mathrm{R})$ 4b-Me $]_{2}{ }^{11 b}$ Hydrogen atoms have been omitted for clarity.

Table 6. Selected Bond Distances, Bond Angles, and Dihedral Angles for $[(R)-4 b-M e]_{2}{ }^{a}$

\begin{tabular}{llll}
\hline \multicolumn{5}{c}{ Bond Distances $(\AA)$} \\
$\mathrm{Zn}(1)-\mathrm{S}(1)$ & $2.389(1)$ & $\mathrm{Zn}(2)-\mathrm{S}(2)$ & $2.390(1)$ \\
$\mathrm{Zn}(1)-\mathrm{S}(2)$ & $2.443(2)$ & $\mathrm{Zn}(2)-\mathrm{S}(1)$ & $2.422(2)$ \\
$\mathrm{Zn}(1)-\mathrm{C}(11)$ & $2.020(5)$ & $\mathrm{Zn}(2)-\mathrm{C}(22)$ & $2.053(4)$ \\
$\mathrm{Zn}(1)-\mathrm{N}(1)$ & $2.101(4)$ & $\mathrm{Zn}(2)-\mathrm{N}(2)$ & $2.107(4)$ \\
\multicolumn{5}{c}{ Bond Angles (deg) } \\
$\mathrm{S}(1)-\mathrm{Zn}(1)-\mathrm{S}(2)$ & $98.99(5)$ & $\mathrm{S}(1)-\mathrm{Zn}(2)-\mathrm{S}(2)$ & $99.84(5)$ \\
$\mathrm{Zn}(1)-\mathrm{S}(1)-\mathrm{Zn}(2)$ & $80.91(5)$ & $\mathrm{Zn}(1)-\mathrm{S}(2)-\mathrm{Zn}(2)$ & $80.25(5)$ \\
\multicolumn{5}{c}{ Dihedral } & Angles (deg) \\
$\mathrm{C}(5)-\mathrm{C}(6)-$ & $107.3(6)$ & $\mathrm{C}(16)-\mathrm{C}(17)-$ & $-17.4(8)$ \\
$\mathrm{C}(7)-\mathrm{C}(8)$ & \multicolumn{5}{c}{$\mathrm{C}(18)-\mathrm{C}(19)$}
\end{tabular}

a The estimated standard deviations are given in parentheses.

three-center bonds with $\mathrm{sp}^{2}$-hybridized sulfur atoms, as al so proposed for the structures of copper (I) aminoarenethiolate complexes. ${ }^{11,12}$ The soft character of $\mathrm{sp}^{2}-\mathrm{s}$ hybrids allows the sulfur atoms in $[(\mathrm{R})-\mathbf{4 b}-\mathbf{M e}]_{2}$ to adopt pyramidal geometries. The rather flat energy surface and its larger size make sulfur a good bridging atom. ${ }^{12 c}$ The relatively small variation between the covalent and the coordinative $\mathrm{Zn}-\mathrm{S}$ bond distances suggests a strong dimeric interaction in $[(\mathrm{R})-\mathbf{4 b}-\mathbf{M e}]_{2}$. This strong dimeric interaction may explain the observed slightly positive nonlinear correlation between the optical purity of the product and that of the precursor catalyst $(R, R)-3 \mathbf{b}$ (vide infra).

1,2-Addition Reactions. The results obtained with the novel zinc bis(aminoarenethiolates) $3 a$ and $(R, R)$ $\mathbf{3 b}$ are in contrast to the reported lack of reactivity of the zinc bis(aminoalkoxides) derived from (dial kylamino)norephedrine. ${ }^{5}$ A possible explanation might that the latter complex is dimeric, as was found for $(R, R)$ $\mathrm{Zn}\left((\mathrm{N} \text {-methylpseudoephedrine })_{2}\right.$ by Enders et al. ${ }^{17}$ This may make the complex unreactive toward diethylzinc and so prevents the generation of the desired organozinc aminoal koxide.

The results reported so far support an underlying mechanism for these (R,R)-3b-, (R)-1c-, and (R)-1dcatalyzed 1,2-addition reactions that has the general characteristics reported by Noyori et al. for the (2S)DAIB-catalyzed reactions ${ }^{4 \mathrm{~b}}$ see (Scheme 3 ). The initial step in both the (R,R)-3- and the (R)-1-catalyzed 1,2addition reactions will be reaction with 1 equiv of $Z n R_{2}$

(17) Enders, D.; Zhu, J .; Raabe, G. Angew. Chem., Int. Ed. Engl. 1996, 35, 1725 .

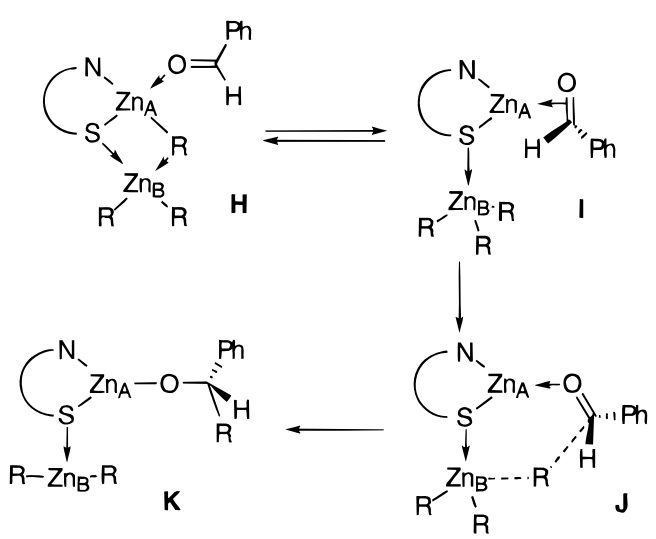

Figure 8. Alternative structures for the proposed key intermediate $\mathbf{H}$ in the zinc-catalyzed 1,2-addition reaction.

\section{Scheme 3}

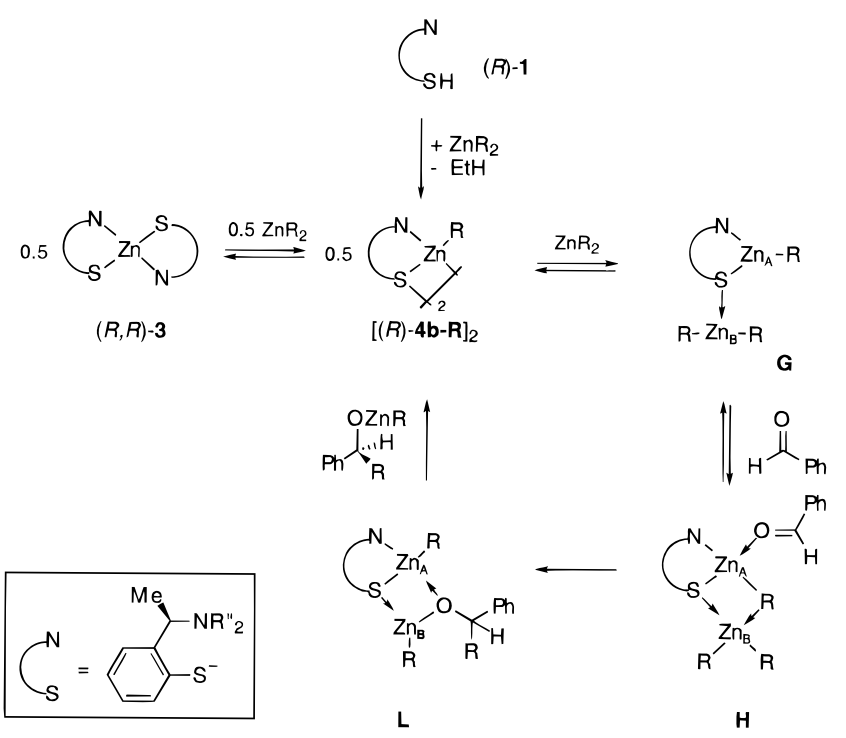

to form the corresponding dimeric organozinc aminoarenethiolates $[(R)-\mathbf{4}-\mathbf{R}]_{2}$. The observed inertness of benzal dehyde toward $[(\mathrm{R})-\mathbf{4 - E} \mathbf{t}]_{2}$ shows that these complexes are not the actual catalysts in the 1,2-addition: the conversion of benzaldehyde requires at least 1 equiv more of $Z n R_{2}$. This second equival ent of $Z n R_{2}$ facilitates the dissociation of the dimer by the formation of coordinatively unsaturated monomeric (R)-4-R (G). Coordination of benzal dehyde to $\mathbf{G}$ gives the productforming intermediate complex $\mathbf{H}$. Such a species (without substrate coordination) has precedents in organoaluminum aminophenolate and aminoal koxide chemistry. ${ }^{18}$ A subsequent transfer of an organyl anion from zinc to the coordinated aldehyde gives $\mathbf{L}$. The catalytic cycle is closed by splitting off the organozinc adduct of (S)$\mathbf{5 b}$ and regenerating of $[(\mathrm{R})-\mathbf{4 - R}]_{2}$. According to this mechanism the low yield of (S)-5c in the reaction of benzaldehyde with the more bulky $\mathrm{Zn}(\mathrm{i}-\mathrm{Pr})_{2}$ can be explained by the reduced accessibility of $\mathbf{H}$ due to steric congestion. This applies even more for the $\eta^{2}-\mathrm{CO}$ intermediate I (see Figure 8). Furthermore, the low yield of (S)-5b in the presence of potentially intermolecularly coordinating thf as a cosolvent can be ascribed to competition between thf and benzaldehyde for a coordination site in $\mathbf{H}$.

(18) (a) Hogerheide, M. P.; Wesseling, M.; J astrzebski, J . T. B. H.; Boersma, J .; Kooijman, H.; Spek, A. L.; van Koten, G. Organometallics 1995, 14, 4483. (b) van Vliet, M. R. P.; van Koten, G.; de Keijser, M. S.; Vrieze, K. Organometallics 1987, 6, 1652. 
Although the solid-state structure of (R)-4b-Me shows it to be a dimer, the association number of (R)-4b-Me in $\mathrm{C}_{6} \mathrm{H}_{6}$ solutions ranges from 2.9 to 3.3 according to cryoscopy, indicating an equilibrium between a dimer and a more highly associated species. ${ }^{11 b}$ Such higher associates are not unprecedented for organozinc aminothiolates, since a tetramer has recently been reported for the structure in solution of the $\mathrm{ZnEt}_{2}$ adduct of the $\mathrm{HCl}$ salt of $\mathrm{N}$-methylephedrine thiol.19b The slightly positive nonlinear relation between the optical purity of (S)-5b and the optical purity of $(R, R)-3 b$ points to the intermediacy of the dimer $[(\mathrm{R})-\mathbf{4}-\mathbf{E t}]_{2},{ }^{20}$ however, $[(\mathrm{R})$ 4-E $t]_{2}$ may be involved in a preequilibrium with $[(R)-$ 4-Et $]_{4}$, similar to the one we have reported for ethylzinc enolates. ${ }^{21}$

The replacement of the $\mathrm{NMe}_{2}$ group in the aminoarenethiolateligand by $\mathrm{N}\left(\mathrm{CH}_{2}\right)_{4}$ or $\mathrm{N}\left(\mathrm{CH}_{2}\right)_{5}$ significantly increases the ee of (S)-12 in the $\mathrm{PhCH}_{2} \mathrm{CH}_{2} \mathrm{CHO} / \mathrm{ZnEt}_{2}$ model reaction. Moreover, the application of the latter ligands not only affects the thermodynamic stability of the product-forming intermediate by giving a higher ee but also accelerates the rate-determining step in this reaction, i.e. the alkyl-transfer step. ${ }^{4}$ These effects are nicely explained by considering $\mathbf{H}$ to be a zinc cation/ zinc anion pair, as the result of an alkyl shift from $Z \mathrm{n}_{\mathrm{A}}$ to $Z n_{B}{ }^{4 b}$ The $Z n_{B}-C$ bonds in this zinc cation/zinc anion pair are much more reactive toward carbonyl substrates because the bonding of three monoanionic organic groups to a divalent zinc atom gives more polar $\mathrm{Zn}_{\mathrm{B}}-\mathrm{C}$ bonds. As regards the intermediacy of such an ionic species, it seems not unlikely that the substrate may coordinate to the Lewis acidic $Z_{\mathrm{A}}$ center via $\eta^{2}$ coordination of the $\mathrm{C}=\mathrm{O}$ bond. A model for such an intermediate based on the structural features of $(R, R)-3 \mathbf{b}$ is schematically depicted in Figure 8 (I). It d early shows that prior $\eta^{2}-\mathrm{CO}$ coordination of the aldehyde will be strongly influenced by the mutual positioning of the $\alpha-M e$ group and the incoming benzaldehyde grouping; i.e, it explains why the chiral zinc(aminoarenethiolate) chelate is so effective in enantioface recognition. Already during this $\eta^{2}$-coordination process the configuration at the $\mathrm{C}=\mathrm{O}$ carbon center becomes fixed. Slipping of the $\mathrm{Zn}$ atom along the $\mathrm{C}=\mathrm{O}$ bond in the direction of the oxygen atom (cf. alkene slipping in $\eta^{2}$-alkene metal bonding) activates the $\mathrm{C}=\mathrm{O}$ carbon atom for nucl eophilic attack by the alkyl group from the zincate moiety. It is noteworthy that the $\mathrm{C}=\mathrm{C}$ bonds in diorganozinc compounds $\mathrm{Zn}\left(\mathrm{CH}_{2} \mathrm{CH}_{2} \mathrm{CH}=\mathrm{CH}_{2}\right)_{2}{ }^{22 \mathrm{a}}$ and $\mathrm{Zn}$ $\left(\mathrm{CH}_{2} \mathrm{C}(\mathrm{t}-\mathrm{Bu})=\mathrm{CHC}(\mathrm{t}-\mathrm{Bu})=\mathrm{CH}_{2}\right)_{2}{ }^{22 \mathrm{~b}}$ show $\eta^{2}$-type interactions with zinc. The existence of intramolecularly coordinated zincate species such as I is supported by the recent isolation and structural characterization of a lithium triorganozincate compound containing a tetracoordinated zinc atom, which is bonded by three monoanionic 2-[1-(dimethylamino)methyl]phenyl ligands, one of which is intramolecularly $\mathrm{C}, \mathrm{N}$-chelated, while the lithium center is coordinated by the nitrogen donors of the other two ligands. ${ }^{23}$ An obvious difference of the

(19) (a) Hof, R. P.; Poelert, M. A.; Peper, N. C. M. W.; Kellogg, R. M. Tetrahedron: Asymmetry 1994, 5, 31. (b) Fitzpatrick, K.; Hulst, R.; Kellogg, R. M. Tetrahedron: Asymmetry 1995, 6, 1861. (c) Kellog, R. M.; Hof, R. P. J . Chem. Soc., Perkin Trans. 1 1996, 1651.

(20) Guillaneux, D.; Zhao, S. H.; Samuel, O.; Rainford, D.; Kagan, H. B. J . Am. Chem. Soc. 1994, 116, 9430.

(21) van der Steen, F. H.; Boersma, J .; Spek, A. L.; van Koten, G. Organometallics 1991, 10, 2467.

(22) (a) Haaland, A.; Lehmkuhl, H.; Nehl, H. Acta. Chem. Scand., Ser. A 1984, 38, 547. (b) Ernst, R. D.; Freeman, J. W.; Swepsto, P. N.; Wilson, D. R. J . Organomet. Chem. 1991, 402, 17. proposed intermediate of $\mathbf{I}$ and the reaction coordinate considered so far is the product-forming step via $\mathbf{J}$ to K. Intermediate $\mathbf{K}$, a 1:1 mixed aminoarenethiolate/ aryloxyzinc species, can disproportionate in the organozinc (arylalkoxide) and the organozinc (aminoarenethiolate) (cf. $[(R)-\mathbf{4 b}-\mathbf{R}]_{2}$ in Scheme 3) species. This reaction sequence relates directly the resting state of the catalyst with the product-forming step.

Finally, the substitution of the $\mathrm{NMe}_{2}$ group by a more basic $\mathrm{N}\left(\mathrm{CH}_{2}\right)_{4}$ or $\mathrm{N}\left(\mathrm{CH}_{2}\right)_{5}$ group results in a stronger $\mathrm{Zn}_{\mathrm{A}}-\mathrm{N}$ interaction in $\mathbf{I}$. Shortening of this $\mathrm{Zn}_{\mathrm{A}}-\mathrm{N}$ bond results in a more efficient transfer of the chiral information from the benzylic carbon atom in the arenethiolate ligand to the zinc center. This in its turn will enhance the differences between the relative thermodynamic stabilities of the si- and recoordinated aldehyde in intermediate $\mathbf{l}$. Another consequence is that shortening of the $Z n_{A}-N$ bond is accompanied by an elongation of the $Z n_{A}-S$ bond. This results in a stronger $Z n_{B}-S$ interaction and therefore in an increase of the polarity of the $Z \mathrm{n}_{\mathrm{B}}-\mathrm{C}$ bonds. This will result in a faster transfer of the organyl group from $Z_{B}$ to the coordinated substrate. Furthermore, the enhanced rate of the catalyzed 1,2-addition reaction will now efficiently compete with the relatively slow background reaction yielding racemic alcohols. ${ }^{15}$

\section{Concluding Remarks}

The potentially $\mathrm{S}, \mathrm{N}$-chelating, monoanionic aminoarenethiolate ligand [ $\left.\mathrm{SC}_{6} \mathrm{H}_{4} \mathrm{CHR}^{\prime} \mathrm{NR}^{\prime \prime}{ }_{2}-2\right]^{-}$, attached to zinc, acts as an excellent nontransferable group in the 1,2-additions of dialkylzinc compounds to aldehydes. The $\gamma$-positioned dimethylamino group causes the formation of a six-membered chelate ring via $\mathrm{Zn}-\mathrm{N}$ bond formation. Due to incorporation of the aryl ring in this six-membered chelatering, the fluxional behavior of this ring is similar to that of five-membered chelate rings. The presence of a chiral benzylic carbon atom in this ring dramatical ly increases the differences between the thermodynamic stabilities of the two possible conformers $\delta$ and $\lambda$.

The chemo- and enantioselectivities obtained with the aminoarenethiolate ligands $\mathbf{b}-\mathbf{d}$ are close to those reported for the DBNE- 5 and the DAIB-catalyzed ${ }^{4}$ enantioselective 1,2-additions. The results illustrate that, although our ligand is based on the absolute minimum of chiral information (only a single $\alpha$-methyl substituent), it is capable of fully controlling the 1,2additions. The question can be asked how simple a chiral auxiliary can be to still be effective in stereochemical control of reactions.

Until very recently, the application of aminothiolates in the enantioselective addition of $\mathrm{ZnEt}_{2}$ to aldehydes was completely unprecedented. During this work, the preparation and successful application of $(1 R, 2 S)-(-)$ $\mathrm{N}, \mathrm{N}^{\prime}$-dialkylthionorephedrine derivatives ${ }^{19,24}$ and of a thio derivative of (S)-N-Boc-prolinol ${ }^{25}$ were reported. Inspired by our results with the aminoarenethiolate ligands, Wirth ${ }^{26}$ al so investigated the structurally analo-

(23) Rijnberg, E.; J astrzebski, J . T. B. H.; Boersma, J .; Kooijman, H.; Veldman, N.; Spek, A. L.; van Koten, G. Organometallics 1997, $16,2239$.

(24) (a) Kang, J ; Lee, J. W.; Kim, J. I. J. Chem. Soc., Chem. Commun. 1994, 2009. (b) Kang, J .; Kim, D. S.; Kim, J . I. Synlett 1994, 842.

(25) Gibson, C. L. Chem. Commun. 1996, 645.

(26) Wirth, T. Tetrahedron Lett. 1995, 36, 7849. 
gous diselenide derivatives. In all these reactions the enantioselectivities obtained with the aminothiolate ligands were found to be superior to those of their aminoal koxide analogs. Especially for the thio derivative of (S)-N-Boc-prolinol and the aminoarenethiolate ligands, in which the chiral information is located on the amino-substituted carbon atoms, this phenomenon can be explained by the difference in basicity between oxygen and sulfur. Sulfur is less basic than oxygen, and therefore, the $\mathrm{Zn}-\mathrm{S}$ bond is longer than the $\mathrm{Zn}-\mathrm{O}$ bond in the aminoalkoxide derivatives. These longer $\mathrm{Zn}-\mathrm{S}$ bonds are accompanied by shorter $\mathrm{Zn}-\mathrm{N}$ bonds, resulting in a more efficient transfer of the chiral information from the ligand to the zinc center in aminothiol ates. In this respect prospective research of the aminothiolate analogs of known al koxide ligand systems, in which the chiral information is located on the amino-substituted carbon atom, should be very promising.

Finally, we formulated some new details of the intermediates along the reaction coordinate of the zinccatalyzed 1,2-addition of di organozinc reagents to aldehydes. This was necessary to be able to explain the effective stereocontrol by the seemingly simple aminoarenethiolate ligand (the same question arose in our studies concerning copper (I) aminoarenethiol ate catalyzed reactions ${ }^{11 b}$ ). In addition to a more compact $\mathrm{Zn}$ coordination sphere we propose prior $\eta^{2}$ coordination of the aldehyde in the stereo-discriminating step which is assisted by concomitant formation of a highly reactive triorganozincate unit that is coordinated to the sulfur donor atom of the chelate-bonded aminoarenethiolate ligand. Detailed computational studies are ongoing to compare this reaction route with the previously reported ones.

\section{Experimental Section}

General Data. All manipulations were carried out using standard Schlenk techniques under an inert atmosphere of dry, oxygen-free nitrogen. dmf was dried on molecular sieves ( $4 \AA$ ) prior to use. $\mathrm{Et}_{2} \mathrm{O}$, toluene, $\mathrm{C}_{6} \mathrm{H}_{6}$, pentane, and hexane were carefully dried and distilled from $\mathrm{N}$ a/benzophenone prior to use. $\mathrm{CH}_{2} \mathrm{Cl}_{2}$ was distilled from $\mathrm{CaH}_{2}$. The starting materials (R)- and (S)- $\mathrm{C}_{6} \mathrm{H}_{5} \mathrm{CH}(\mathrm{Me}) \mathrm{NH}_{2}$ with an optical purity of $96 \%$ ee were obtained from J anssen Chimica; (R)- $\mathrm{C}_{6} \mathrm{H}_{5} \mathrm{CH}(\mathrm{Me}) \mathrm{NH}_{2}$ with an optical purity of $99.9 \%$ ee was obtained from Fluka. The former quality was used in all reactions unless stated otherwise. All other standard chemicals were purchased from Aldrich Chemical Co. and J anssen Chimica. (R)-MeZn $\left(\mathrm{SC}_{6} \mathrm{H}_{4^{-}}\right.$ $\left.\mathrm{CH}(\mathrm{Me}) \mathrm{NMe}_{2}-2\right)$ ((R)-4b-Me), ${ }^{11 \mathrm{~b}}$ dry $\mathrm{ZnCl}_{2},{ }^{27}$ and $\mathrm{Zn}(\mathrm{i}-\mathrm{Pr})_{2}{ }^{28}$ were prepared according to literature procedures. ${ }^{1} \mathrm{H}$ and ${ }^{13} \mathrm{C}$ NMR spectra were recorded at ambient temperature at 200 and $50 \mathrm{MHz}$. Chemical shifts $(\delta)$ are given in ppm relative to $\mathrm{SiMe}_{4}$ as an external standard. Melting points are uncorrected. GC analyses were performed on a gas chromatograph using a 30 m DB 17 (liquid phase) capillary column: temperature program $1,100^{\circ} \mathrm{C}, 3 \mathrm{~min}, 20^{\circ} \mathrm{C} \mathrm{min}-1,270^{\circ} \mathrm{C}, 10 \mathrm{~min}$; temperature program $2,100{ }^{\circ} \mathrm{C}, 0 \mathrm{~min}, 20^{\circ} \mathrm{C} \mathrm{min}-1,270{ }^{\circ} \mathrm{C}$, $15 \mathrm{~min}$. GC-MS was carried out using a Unicam Automass spectrometer fitted with a Unicam 610 series gas chromatograph. Mass spectra obtained under electron ionization (EI) conditions (70 eV) were recorded by linear scanning from $\mathrm{m} / \mathrm{z}$ 50 to 500. HPLC was performed on a Diacel chiralcel OD column, $25 \mathrm{~cm} \times 4.6 \mathrm{~mm}$. Optical rotations were determined on a Perkin-EImer 241 polarimeter. Elemental analyses were obtained from Dornis und Kolbe Mikroanalytisches Laboratorium, Mülheim a.d. Ruhr, Germany.

(27) Nützel, K. In Methoden Org. Chem. (Houben-Weyl), 4th Ed. 1973, 13 (part 2a), 595.

(28) Hamilton, R. T.; Butler, J . A. V. J . Chem. Soc. 1932, 2283.
NMR and GC-MS data on the catalysts and related compounds and the complete analytical data on the organic products of the addition reactions are provided as Supporting Information.

Preparation of $(\mathbf{R})-\mathbf{C}_{6} \mathbf{H}_{5} \mathbf{C H}(\mathbf{M e}) \mathbf{N}\left(\mathbf{C H}_{2}\right)_{4}$. To a solution of (R) $-\mathrm{C}_{6} \mathrm{H}_{4} \mathrm{CH}(\mathrm{Me}) \mathrm{NH}_{2}(10 \mathrm{~mL} ; 0.08 \mathrm{~mol})$ in $\mathrm{dmf}(100 \mathrm{~mL})$ was added $\mathrm{NaHCO}_{3}(34 \mathrm{~g} ; 0.4 \mathrm{~mol})$ and $\mathrm{Br}\left(\mathrm{CH}_{2}\right)_{4} \mathrm{Br}(9.7 \mathrm{~mL} ; 0.08$ $\mathrm{mol})$. The mixture was heated to $120{ }^{\circ} \mathrm{C}$ for $17 \mathrm{~h}$. After it was cooled to room temperature, the mixture was filtered and the residue was washed with $\mathrm{Et}_{2} \mathrm{O}(2 \times 100 \mathrm{~mL})$. The combined organic fractions were washed with water $(3 \times 50$ $\mathrm{mL}$ ). The organic layer of the combined filtrate and washings was separated from the water layer and evaporated in vacuo. The product mixture was redissolved in hexane $(50 \mathrm{~mL})$. The hexane solution was extracted with water $(2 \times 50 \mathrm{~mL})$ and dried on $\mathrm{Na}_{2} \mathrm{SO}_{4}$. After filtration the solvent was removed in vacuo. Short-path distillation at reduced pressure afforded the product as a colorless oil, yield $8.66 \mathrm{~g}(63 \%) .[\alpha]^{20} \mathrm{D}=$ $+50.3^{\circ}(\mathrm{MeOH})$.

Preparation of (R)- $\mathbf{C}_{6} \mathbf{H}_{5} \mathbf{C H}(\mathbf{M e}) \mathbf{N}\left(\mathrm{CH}_{2}\right)_{5}$. The synthetic procedure is identical with that described for (R)- $\mathrm{C}_{6} \mathrm{H}_{5} \mathrm{CH}$ (Me)N $\left(\mathrm{CH}_{2}\right)_{4}$, with (R)- $\mathrm{C}_{6} \mathrm{H}_{4} \mathrm{CH}(\mathrm{Me}) \mathrm{NH}_{2}(20 \mathrm{~mL} ; 0.15 \mathrm{~mol})$, $\mathrm{NaHCO}_{3}(68 \mathrm{~g} ; 0.8 \mathrm{~mol})$, and $\mathrm{Br}\left(\mathrm{CH}_{2}\right)_{5} \mathrm{Br}(22.0 \mathrm{~mL} ; 0.16 \mathrm{~mol})$ as starting materials. The product was obtained as a colorless oil, yield $20.1 \mathrm{~g}(69 \%)$. $[\alpha]^{20}{ }_{\mathrm{D}}=+32.3^{\circ}(\mathrm{MeOH})$.

[(R)- $\left.\mathbf{L i}\left(\mathbf{C}_{6} \mathbf{H}_{4} \mathbf{C H}(\mathbf{M e}) \mathbf{N}\left(\mathbf{C H}_{2}\right)_{\mathbf{4}}-\mathbf{2}\right)\right]_{\mathbf{4}}$ was prepared according to a published procedure, ${ }^{10}$ with (R) $-\mathrm{C}_{6} \mathrm{H}_{5} \mathrm{CH}(\mathrm{Me}) \mathrm{N}\left(\mathrm{CH}_{2}\right)_{4}(3.69$ g; $21.0 \mathrm{mmol}$ ) and t-BuLi (14.1 mL of a $1.5 \mathrm{M}$ solution in pentane, $21.0 \mathrm{mmol}$ ) as starting materials: yield $2.44 \mathrm{~g} \mathrm{(3.37}$ $\mathrm{mmol}, 64 \%) ; \mathrm{mp} 168^{\circ} \mathrm{C}$.

Preparation of $\left[(\mathrm{R})-\mathrm{Li}\left(\mathrm{C}_{6} \mathrm{H}_{4} \mathbf{C H}(\mathrm{Me}) \mathbf{N}\left(\mathrm{CH}_{2}\right)_{5}-2\right)\right]_{4}$. The synthetic procedure is identical with that described for $[(\mathrm{R})$ $\left.\mathrm{Li}\left(\mathrm{C}_{6} \mathrm{H}_{4} \mathrm{CH}(\mathrm{Me}) \mathrm{N}\left(\mathrm{CH}_{2}\right)_{4}-2\right)\right]_{4}$, with $(\mathrm{R})-\mathrm{C}_{6} \mathrm{H}_{5} \mathrm{CH}(\mathrm{Me}) \mathrm{N}\left(\mathrm{CH}_{2}\right)_{5}(4.73$ g; $25.0 \mathrm{mmol}$ ) and t-BuLi (16.7 mL of a $1.5 \mathrm{M}$ solution in pentane, $25.0 \mathrm{mmol}$ ) as starting materials: yield $4.18 \mathrm{~g} \mathrm{(5.36}$ $\mathrm{mmol}, 86 \%) ; \mathrm{mp}>180{ }^{\circ} \mathrm{C}$.

(R)- $\left.\mathbf{H S C}_{6} \mathbf{H}_{\mathbf{4}} \mathbf{C H}(\mathbf{M e}) \mathbf{N}\left(\mathbf{C H}_{\mathbf{2}}\right)_{\mathbf{4}} \mathbf{- 2}(\mathbf{R})-\mathbf{- 1 C}\right)$ was prepared according to a published procedure, ${ }^{11 a}$ with $\left[(\mathrm{R})-\mathrm{Li}\left(\mathrm{C}_{6} \mathrm{H}_{4} \mathrm{CH}\right.\right.$ (Me)N $\left.\left.\left(\mathrm{CH}_{2}\right)_{4}-2\right)\right]_{4}(2.44 \mathrm{~g} ; 3.37 \mathrm{mmol})$, sublimed $\mathrm{S}_{8}(0.43 \mathrm{~g} ; 1.68$ $\mathrm{mmol})$, and a solution of $\mathrm{HCl}(1.40 \mathrm{~mL}$ of a $9.7 \mathrm{M}$ solution in $\mathrm{H}_{2} \mathrm{O}$; $\left.13.6 \mathrm{mmol}\right)$ in thf $(10 \mathrm{~mL})$ as starting materials. Analytically pure (R)-1c was isolated by sublimation at 120 ${ }^{\circ} \mathrm{C}$ at reduced pressure, foll owed by subsequent washing with $\mathrm{Et}_{2} \mathrm{O}(10 \mathrm{~mL})$. Yield: $1.06 \mathrm{~g}(38 \%)$. Mp: $123^{\circ} \mathrm{C}$. Anal. Calcd for $\mathrm{C}_{11} \mathrm{H}_{17} \mathrm{NS}$ : C, 69.52; $\mathrm{H}, 8.26 ; \mathrm{N}, 6.76$. Found: $\mathrm{C}, 69.34 ; \mathrm{H}$, 8.31; N, 6.72.

(R)-HSC ${ }_{6} \mathbf{H}_{4} \mathbf{C H}(\mathbf{M e}) \mathbf{N}\left(\mathbf{C H}_{2}\right)_{5}-\mathbf{2}((\mathbf{R})-\mathbf{1 d})$ was prepared according to a published procedure, $11 \mathrm{a}$ with $\left[(\mathrm{R})-\mathrm{Li}\left(\mathrm{C}_{6} \mathrm{H}_{4} \mathrm{CH}\right.\right.$ (Me)N $\left.\left.\left(\mathrm{CH}_{2}\right)_{5}-2\right)\right]_{4}(4.18 \mathrm{~g} ; 5.36 \mathrm{mmol})$, sublimed $\mathrm{S}_{8}(0.69 \mathrm{~g} ; 2.69$ $\mathrm{mmol})$, and a solution of $\mathrm{HCl}(2.2 \mathrm{~mL}$ of a $9.7 \mathrm{M}$ solution in $\left.\mathrm{H}_{2} \mathrm{O} ; 21.0 \mathrm{mmol}\right)$ in thf $(10 \mathrm{~mL})$ as starting materials. Analytically pure (R)-1d was isolated by sublimation at 140 ${ }^{\circ} \mathrm{C}$ at reduced pressure, followed by subsequent washing with $\mathrm{Et}_{2} \mathrm{O}(10 \mathrm{~mL})$. Yield: $1.24 \mathrm{~g}(27 \%)$. $\mathrm{Mp}: 139^{\circ} \mathrm{C}$. Anal. Calcd for $\mathrm{C}_{12} \mathrm{H}_{19} \mathrm{NS}$ : C, 70.54; $\mathrm{H}, 8.65 ; \mathrm{N}, 6.33$. Found: $\mathrm{C}, 70.49 ; \mathrm{H}$, 8.59; N, 6.32 .

Mes $\mathrm{Si}_{-} \mathbf{S C}_{6} \mathbf{H}_{4} \mathbf{C H}_{2} \mathbf{N M e}_{2}-\mathbf{2}$ (2a) was prepared according to the literature procedure; however, ${ }^{13} \mathrm{C}$ NMR data were not reported. ${ }^{11 b}$

(R)-Me $\mathbf{M}_{3} \mathbf{S i}-\mathbf{S C}_{6} \mathbf{H}_{4} \mathbf{C H}(\mathbf{M e}) \mathbf{N M e}_{2}-\mathbf{2}$ ((R)-2b) was prepared according to the literature procedure; however, ${ }^{13} \mathrm{C}$ NMR data were not reported. ${ }^{11 b}$

(R)-Me $\mathbf{S}_{3} \mathrm{Si}-\mathbf{S C}_{6} \mathrm{H}_{4} \mathbf{C H}(\mathbf{M e}) \mathbf{N}\left(\mathrm{CH}_{\mathbf{2}}\right)_{\mathbf{4}} \mathbf{- 2}((\mathbf{R})-\mathbf{2 c})$ was prepared according to the literature procedure with a slightly modified workup procedure, ${ }^{11 \mathrm{~b}}$ with $\left[(\mathrm{R})-\mathrm{Li}\left(\mathrm{C}_{6} \mathrm{H}_{4} \mathrm{CH}(\mathrm{Me}) \mathrm{N}\left(\mathrm{CH}_{2}\right)_{4}-2\right)\right]_{4}$ (1.75 g; $2.42 \mathrm{mmol}$ ), sublimed $\mathrm{S}_{8}\left(0.31 \mathrm{~g} ; 1.21 \mathrm{mmol}\right.$ ), and $\mathrm{Me}_{3^{-}}$ $\mathrm{SiCl}(1.30 \mathrm{~mL} ; 10.24 \mathrm{mmol})$ as starting materials. After the reaction all volatiles were removed in vacuo and the remaining suspension was extracted with pentane $(100 \mathrm{~mL})$. The pentane extract was evaporated in vacuo to afford the crude product as a colorless oil, which was purified by a short-path distillation at reduced pressure; yield $2.32 \mathrm{~g}$ (8.30 mmol; 86\%). 
(R)-Me Si-SC $_{6} \mathbf{H}_{4} \mathbf{C H}(\mathrm{Me}) \mathbf{N}\left(\mathrm{CH}_{2}\right)_{5}-\mathbf{2}((\mathbf{R})-2 \mathrm{~d})$ was prepared according to the procedure for $(\mathrm{R})-\mathbf{2 c}$, with $\left[(\mathrm{R})-\mathrm{Li}\left(\mathrm{C}_{6} \mathrm{H}_{4} \mathrm{CH}\right.\right.$ (Me)N $\left.\left.\left(\mathrm{CH}_{2}\right)_{5}-2\right)\right]_{4}(2.48 \mathrm{~g} ; 3.18 \mathrm{mmol}$ ), sublimed S $(0.41 \mathrm{~g} ; 1.60$ $\mathrm{mmol})$, and $\mathrm{Me}_{3} \mathrm{SiCl}(1.65 \mathrm{~mL} ; 13.00 \mathrm{mmol})$ as starting materials. Yield after distillation: $2.73 \mathrm{~g}$ (9.30 mmol; 73\%).

Preparation of $\mathrm{Zn}\left(\mathrm{SC}_{6} \mathrm{H}_{\mathbf{4}} \mathbf{C H}_{\mathbf{2}} \mathbf{N M e}_{2}-\mathbf{2}\right)_{\mathbf{2}}$ (3a). To a stirred solution of $\mathbf{2 a}$ (5.31 g; $22.18 \mathrm{mmol})$ in $\mathrm{CH}_{2} \mathrm{Cl}_{2}(40 \mathrm{~mL})$ was added $\mathrm{ZnCl}_{2}\left(17.50 \mathrm{~mL}\right.$ of a $0.63 \mathrm{M}$ solution in $\mathrm{Et}_{2} \mathrm{O} ; 11.03$ $\mathrm{mmol}$ ) at room temperature. After the mixture was stirred for $1 \mathrm{~h}$, all volatiles were removed in vacuo to afford a colorless powder. The crude material was washed with pentane $(2 \times$ $25 \mathrm{~mL}$ ) and dried in vacuo, yielding $4.35 \mathrm{~g}$ (10.93 mmol; 99\%) of powder. Crystallization from $\mathrm{CH}_{2} \mathrm{Cl}_{2}$ at $-30{ }^{\circ} \mathrm{C}$ afforded 3a as colorless crystals. Anal. Calcd for $\mathrm{C}_{18} \mathrm{H}_{24} \mathrm{~N}_{2} \mathrm{~S}_{2} \mathrm{Zn}$ : C, 54.33; H, 6.08; N, 7.04. Found: C, 54.06; H, 5.91; N, 6.96. $\mathrm{Mp}:>180^{\circ} \mathrm{C}$.

Preparation of $(\mathrm{R}, \mathrm{R})-\mathrm{Zn}\left(\mathrm{SC}_{6} \mathrm{H}_{4} \mathrm{CH}(\mathrm{Me}) \mathrm{NMe}_{2}-2\right)_{2}$ ((R,R)3b). To a stirred suspension of $\mathrm{ZnCl}_{2}(3.38 \mathrm{~g} ; 24.8 \mathrm{mmol})$ in $\mathrm{C}_{6} \mathrm{H}_{6}(50 \mathrm{~mL})$ was added (R)-2b (12.57 g; $\left.49.83 \mathrm{mmol}\right)$ in $\mathrm{C}_{6} \mathrm{H}_{6}$ $(20 \mathrm{~mL})$ at room temperature. After it was stirred for $48 \mathrm{~h}$, the slightly turbid solution was filtered, and subsequently all volatiles were removed in vacuo. The resulting solid was washed with pentane $(20 \mathrm{~mL})$ and dried in vacuo to afford the product as a colorless powder, yield $10.45 \mathrm{~g}$ (99\%). Crystallization from toluene at $-30^{\circ} \mathrm{C}$ afforded $(R, R)-3 b$ as colorless crystals. Recrystallization from toluene/ $\mathrm{CH}_{2} \mathrm{Cl}_{2}$ at $-30{ }^{\circ} \mathrm{C}$ afforded crystals suitable for X-ray diffraction. Anal. Calcd for $\mathrm{C}_{20} \mathrm{H}_{28} \mathrm{~N}_{2} \mathrm{~S} 2 \mathrm{Zn}$ : C, 56.40; $\mathrm{H}, 6.63 ; \mathrm{N}, 6.58$. Found: $\mathrm{C}, 56.44$; $\mathrm{H}, 6.66$; $\mathrm{N}, 6.63$. $\mathrm{Mp}:>180^{\circ} \mathrm{C}$. Molecular weight determination by cryoscopy ( $1.73 \mathrm{~g}$ in $38.95 \mathrm{~g}$ of $\mathrm{C}_{6} \mathrm{H}_{6}$ ): calcd for monomer 426, found 460.

Preparation of $\mathrm{MeZn}\left(\mathrm{SC}_{6} \mathrm{H}_{4} \mathrm{CH}_{2} \mathrm{NMe}_{2}-2\right)$ (4a-Me). To an in situ prepared solution of $\mathrm{MeZnCl}$ from $\mathrm{ZnCl}_{2}(6.0 \mathrm{~mL}$ of a $0.63 \mathrm{M}$ solution in $\left.\mathrm{Et}_{2} \mathrm{O} ; 3.78 \mathrm{mmol}\right)$ and $\mathrm{ZnMe}_{2}(2.0 \mathrm{~mL}$ of a $2.0 \mathrm{M}$ solution in toluene; $4.0 \mathrm{mmol})$ in $\mathrm{C}_{6} \mathrm{H}_{6}(20 \mathrm{~mL})$ was added $2 \mathbf{2 a}(1.79 \mathrm{~g} ; 7.48 \mathrm{mmol})$ in $\mathrm{C}_{6} \mathrm{H}_{6}(40 \mathrm{~mL})$. The resulting suspension was stirred for 15 min before all volatiles were removed in vacuo. The crude material was washed with pentane $(2 \times 25 \mathrm{~mL})$ and dried in vacuo yielding $1.83 \mathrm{~g}(7.42$ mmol; 99\%) of a colorless powder. Anal. Calcd for $\mathrm{C}_{10} \mathrm{H}_{15^{-}}$ NSZn: C, 48.69; H, 6.13; N, 5.68. Found: C, 48.54; H, 6.03; $\mathrm{N}$, 5.56. Mp: $140{ }^{\circ} \mathrm{C} \mathrm{dec}$.

Preparation of EtZn( $\left.\mathrm{SC}_{6} \mathrm{H}_{4} \mathrm{CH}_{2} \mathrm{NMe}_{2}-2\right)(4 a-E t)$. The complex 4a-Et was prepared according to the procedure described for $\mathbf{4 a - M e}$. With $\mathbf{2 a}(1.01 \mathrm{~g} ; 4.22 \mathrm{mmol})$, EtZnCl, in situ prepared from $\mathrm{ZnCl}_{2}\left(6.60 \mathrm{~mL}\right.$ of a $0.32 \mathrm{M}$ solution in $\mathrm{Et}_{2} \mathrm{O}$; $2.11 \mathrm{mmol}$ ), and $\mathrm{ZnEt}_{2}(2.20 \mathrm{~L}$ of a $1.0 \mathrm{M}$ solution in hexane; $2.20 \mathrm{mmol}$ ) as starting materials, 4a-Et was obtained as a col orless powder, yield $1.09 \mathrm{~g}$ (4.18 mmol; 99\%). Mp: $145^{\circ} \mathrm{C}$ dec.

Preparation of (R)-MeZn( $\left.\mathrm{SC}_{6} \mathrm{H}_{4} \mathrm{CH}(\mathrm{Me}) \mathrm{NMe}_{2}-2\right)((\mathrm{R})-$ 4b-Me). (R)-4b-Me was prepared via an alternative procedure. To a solution of (R,R)-3b (1.27 g; $2.98 \mathrm{mmol})$ in $\mathrm{C}_{6} \mathrm{H}_{6}$ $(15 \mathrm{~mL})$ was added $\mathrm{ZnMe}_{2}(1.5 \mathrm{~mL}$ of a $2.0 \mathrm{M}$ solution in toluene; $3.0 \mathrm{mmol}$ ). After $10 \mathrm{~min}$ the solvent was removed in vacuo. The resulting solid was washed with pentane $(20 \mathrm{~mL})$ and dried in vacuo to afford (R)-4b-Me as a colorless powder,

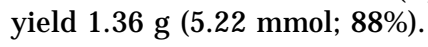

Preparation of (R)-EtZn( $\left.\mathrm{SC}_{6} \mathrm{H}_{4} \mathbf{C H}(\mathrm{Me}) \mathrm{NMe}_{2}-2\right)$ ((R)-4bEt). (R)-4b-Et was prepared similarly to the procedure described for (R)-4b-Me. With (R,R)-3b (1.05 g; $2.47 \mathrm{mmol})$ and $\mathrm{ZnEt}_{2}$ ( $2.5 \mathrm{~mL}$ of a $1.0 \mathrm{M}$ solution in hexanes; $2.50 \mathrm{mmol}$ ) as starting materials, (R)-4b-Et was obtained as a colorless powder, yield $1.29 \mathrm{~g}$ (4.70 mmol; 95\%). Anal. Found: C, 52.46; $\mathrm{H}, 6.82 ; \mathrm{N}, 5.15$. Mp: $135^{\circ} \mathrm{C}$ dec.

Preparation of (R)-MeZn( $\left.\mathrm{SC}_{6} \mathrm{H}_{4} \mathrm{CH}(\mathrm{Me}) \mathrm{N}\left(\mathrm{CH}_{2}\right)_{4}-2\right)((\mathrm{R})-$ 4c-Me). To a stirred suspension of (R)-1c (0.74 g; $3.57 \mathrm{mmol})$ in $\mathrm{C}_{6} \mathrm{H}_{6}(40 \mathrm{~mL})$ was added carefully an excess of $\mathrm{ZnMe}_{2}(2.50$ $\mathrm{mL}$ of a $2.0 \mathrm{M}$ solution in toluene; $5.0 \mathrm{mmol}$ ) at room temperature. After it was stirred for $17 \mathrm{~h}$, the cloudy solution was filtered and subsequently all volatiles were evaporated under reduced pressure. The resulting solid was washed with pentane (20 mL) and dried in vacuo to afford (R)-4c-Me as a colorless powder, yield $0.58 \mathrm{~g}(57 \%)$. $\mathrm{Mp}: 112{ }^{\circ} \mathrm{C} \mathrm{dec}$.

Preparation of (R)-MeZn( $\left.\mathrm{SC}_{6} \mathrm{H}_{4} \mathrm{CH}(\mathrm{Me}) \mathrm{N}\left(\mathrm{CH}_{2}\right)_{5}-2\right)((\mathrm{R})$ 4d-Me). (R)-4d-Me was prepared similarly to the procedure described for (R)-4c-Me. The reaction of (R)-1d (1.43 g; 6.46 $\mathrm{mmol}$ ) and $\mathrm{ZnMe}_{2}(4.0 \mathrm{~mL}$ of a $2.0 \mathrm{M}$ solution in toluene; 8.0 $\mathrm{mmol}$ ) afforded the product as a colorless powder, yield $1.33 \mathrm{~g}$ (68\%). Mp: $117^{\circ} \mathrm{C}$ dec.

General Procedure for 3a- and (R,R)-3b-Catalyzed 1,2Addition Reactions. In a typical experiment $\mathrm{ZnEt}_{2}(11.0 \mathrm{~mL}$ of a $1.0 \mathrm{M}$ solution in toluene, $11.0 \mathrm{mmol}$ ) was added to a stirred solution containing uncrystallized $(R, R)-3 \mathbf{b}(4.0 \mathrm{~mL}$ of a $0.05 \mathrm{M}$ solution in toluene, $0.20 \mathrm{mmol})$ in toluene $(30 \mathrm{~mL})$ at room temperature. After $5 \mathrm{~min} 10.0 \mathrm{mmol}$ of the appropriate al dehyde in toluene $(20 \mathrm{~mL})$ was added, and the reaction mixture was stirred for $17 \mathrm{~h}$ at room temperature. The reaction mixture was quenched with $20 \mathrm{~mL}$ of a saturated $\mathrm{NH}_{4-}$ $\mathrm{Cl}$ solution. The organic layer was separated, and the water layer was extracted with $\mathrm{CH}_{2} \mathrm{Cl}_{2}(2 \times 20 \mathrm{~mL})$; the combined organic layers were dried on $\mathrm{Na}_{2} \mathrm{SO}_{4}$ and concentrated in vacuo. Purification of the crude products was done by distillation at reduced pressure.

General Procedure for (R)-1c- and (R)-1d-Catalyzed 1,2-Addition Reactions. The procedure was identical with that described above, with (R)-1c $(0.08 \mathrm{~g} ; 0.4 \mathrm{mmol}), \mathrm{ZnEt}_{2}$ (11.0 mL of a $1.0 \mathrm{M}$ solution in toluene, $11.0 \mathrm{mmol}$ ), and 10.0 $\mathrm{mmol}$ of the appropriate aldehyde in toluene as starting materials.

All analytical data for the organic products of the 1,2addition reactions are provided as Supplementary I nformation.

Stoichiometric Reaction of Benzaldehyde with (R)4b-Et. To a solution of separately prepared (R)-4b-Et $(0.42$ g; $1.53 \mathrm{mmol})$ in toluene $(40 \mathrm{~mL})$ was added benzaldehyde $(0.15$ $\mathrm{mL} ; 1.48 \mathrm{mmol}$ ) at room temperature, and the reaction mixture was stirred for $17 \mathrm{~h}$. A sample for GC analysis was obtained after hydrolysis with a saturated aqueous solution of $\mathrm{NH}_{4} \mathrm{Cl}$. The product ratio was determined by GC analysis.

Stoichiometric Reaction of Benzaldehyde, (R)-4b-Et, and $\mathbf{Z n E} \mathbf{t}_{2}$. To a stirred solution of $(R, R)-3 b(0.64 \mathrm{~g} ; 1.50$ $\mathrm{mmol})$ and $\mathrm{ZnEt}_{2}(4.50 \mathrm{~mL}$ of a $4.50 \mathrm{M}$ solution in hexane; $13.0 \mathrm{mmol}$ ) in toluene $(40 \mathrm{~mL})$ was added benzaldehyde $(0.31$ g; $2.92 \mathrm{mmol}$ ) at room temperature, and the reaction mixture was stirred for $17 \mathrm{~h}$. Samples for GC and HPLC analyses were obtained after hydrolysis with a saturated aqueous solution of $\mathrm{NH}_{4} \mathrm{Cl}$. The product ratio was determined by $\mathrm{GC}$ analysis (program 1): $t_{R}(5 b)=7.85 \mathrm{~min}(100 \%)$. The ee $(92 \%)$ was determined by HPLC analysis.

(R)-4b-Et-Catalyzed Reaction of Benzaldehyde with $\mathbf{Z n E t}_{\mathbf{2}}$. To a solution of separately prepared (R)-4b-Et $(0.08$ g; $0.29 \mathrm{mmol})$ and $\mathrm{ZnEt}_{2}(8.0 \mathrm{~mL}$ of a $1.0 \mathrm{M}$ solution in hexane; $8.0 \mathrm{mmol})$ in toluene $(40 \mathrm{~mL})$ was added benzal dehyde $(0.75$ $\mathrm{mL} ; 7.38 \mathrm{mmol}$ ) at room temperature, and the reaction mixture was stirred for $17 \mathrm{~h}$. Samples for GC and HPLC analyses were obtained after hydrolysis with a saturated aqueous solution of $\mathrm{NH}_{4} \mathrm{Cl}$. The product ratio was determined by $\mathrm{GC}$ analysis and the ee of $\mathbf{5 b}(92 \%)$ was determined by HPLC analysis.

Cosolvent Effect. A solution of $(R, R)-3 b(4.0 \mathrm{~mL}$ of a 0.05 $\mathrm{M}$ solution in toluene, $0.20 \mathrm{mmol}$ ) in t-BuOMe, $E t_{2} \mathrm{O}$, or thf $(50 \mathrm{~mL})$ was stirred at room temperature. After $5 \mathrm{~min}$ benzal dehyde ( $1.0 \mathrm{~mL} ; 9.84 \mathrm{mmol})$ was added and the reaction mixture was stirred for $17 \mathrm{~h}$ at room temperature. Samples for GC and HPLC analyses were obtained after hydrolysis with a saturated aqueous solution of $\mathrm{NH}_{4} \mathrm{Cl}$. The product ratio was determined by GC analysis. The ee (89\%, 83\%, and $74 \%$ ) was determined by HPLC analysis.

ee Variation of $(\mathbf{R}, \mathbf{R})-3 \mathbf{b}$. To a stirred solution containing $(R, R)-3 b(9.0,8.0,7.0$, or $6.0 \mathrm{~mL}$ of a $0.02 \mathrm{M}$ solution in toluene; $0.18,0.16,0.14$, or $0.12 \mathrm{mmol})$ in toluene $(25 \mathrm{~mL})$ was added $(\mathrm{S}, \mathrm{S})-3 \mathbf{b}(1.0,2.0,3.0$, or $4.0 \mathrm{~mL}$ of a $0.02 \mathrm{M}$ solution in toluene; $0.02,0.04,0.06$, or $0.08 \mathrm{mmol}$ ) at room temperature to generate in situ (R, R)-3b with an optical purity of $80 \%, 60 \%, 40 \%$, and $20 \%$ ee, respectively. After 5 min $\mathrm{ZnEt}_{2}(11.0 \mathrm{~mL}$ of a $1.0 \mathrm{M}$ solution in toluene, $11.0 \mathrm{mmol}$ ) and benzaldehyde $(1.0 \mathrm{~mL} ; 9.84$ 
mmol) were added and the reaction mixture was stirred for $17 \mathrm{~h}$ at room temperature. Samples for GC and HPLC analyses were obtained after hydrolysis with a saturated aqueous solution of $\mathrm{NH}_{4} \mathrm{Cl}$. The product ratio was determined by GC analysis and the ee's by HPLC analysis. A similar experiment was carried out with $2 \mathrm{~mol} \%$ of $(\mathrm{R}, \mathrm{R})$-3b derived from $99.9 \%$ ee $(\mathrm{R})-\mathrm{C}_{6} \mathrm{H}_{5} \mathrm{C}(\mathrm{Me}) \mathrm{HNMe}_{2}$. This gave (S)-5b in $>99 \%$ yield with an ee of $94 \%$.

X-ray Data Collection, Structure Determination, and Refinement of (R,R)-3b. X-ray data were collected on an Enraf-Nonius CAD4T/rotating anode diffractometer for a colorless transparent crystal which was glued on top of a glass fibre. Accurate unit-cell parameters and an orientation matrix were derived from the setting angles of 25 well-centered reflections (SET4) 29 in the range $9<\theta<14^{\circ}$. The unit-cell parameters were checked for the presence of higher lattice symmetry. ${ }^{30}$ Data were corrected for Lorentz and polarization effects. An empirical absorption correction was applied (DIFABS $^{31}$ as implemented in PLATON ${ }^{32}$ ). The structure was solved by direct methods and subsequent difference Fourier techniques (SHELXS86). ${ }^{33}$ Refinement on $\mathrm{F}^{2}$ was carried out by full-matrix least-squares techniques (SHELXL93) ${ }^{34}$ using no observance criterion. The correct absolute structure adopted for the structure of $(R, R)$-3b was indicated by the Flack parameter ${ }^{35}$ value of 0.04(4). Hydrogen atoms were introduced on calculated positions and refined riding on their carrier atoms. All non-hydrogen atoms were refined with anisotropic atomic displacement parameters. The hydrogen atoms were refined with a fixed isotropic atomic displacement parameter related to the value of the equivalent isotropic atomic displacement parameter of their carrier atom by a factor of 1.2 for the benzylic and aromatic hydrogens and a factor of 1.5 for the methyl hydrogen atoms. Weights were optimized in the final refinement cydes. Neutral atom scattering factors and anomalous dispersion corrections were taken from ref 36. Geometrical calculations and illustrations were performed with PLATON. ${ }^{32}$ All calculations were performed on a DEC5000 cluster. Experimental data and numerical details of the structure determination and refinement are collected in Table 7.

(29) de Boer, J . L.; Duisenberg, A. J . M. Acta Crystallogr. 1984, A40, C410.

(30) Spek, A. L. J . Appl. Crystallogr. 1988, 21, 578.

(31) Walker, N.; Stuart, D. Acta Crystallogr. 1983, A39, 158.

(32) Spek, A. L. Acta Crystallogr. 1990, A46, C34.

(33) Sheldrick, G. M. SHELXS86: Program for Crystal Structure Determination; University of Göttingen, Göttingen, Germany, 1986.

(34) Sheldrick, G. M. SHELXL93: Program for Crystal Structure Refinement; University of Göttingen, Göttingen, Germany, 1993.

(35) Flack, H. D. Acta Crystallogr. 1983, A39, 876.

(36) Wilson, A. J . C., Ed. International Tables for Crystall ography; Kluwer Academic: Dordrecht, The Netherlands, 1992; Vol. C.
Table 7. Crystallographic Data and Details of the Structure Determination for $(R, R)-3 b$

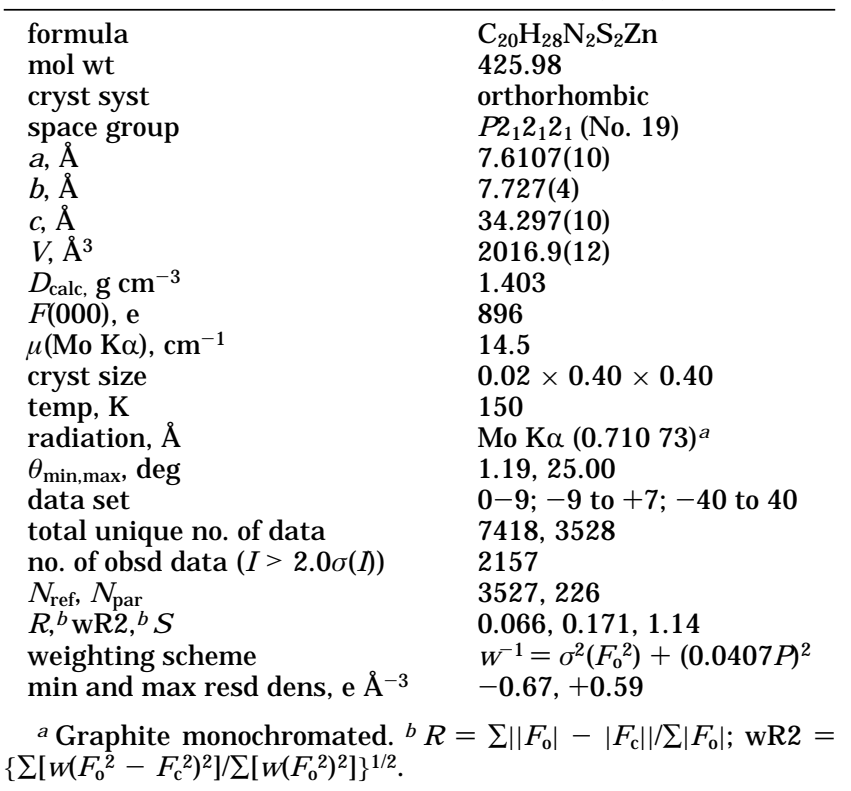

Computational Details. The molecular mechanics calculations were performed with CAChe WorkSystem software, Version 3.8, on an Apple Power Macintosh 8100 equipped with two CAChe CXP coprocessors. The isomers of $(R, R)-3 \mathbf{b}$ were modeled using an augmented MM2 force field.

Acknowledgment. We thank Mr. D. Kruis for carrying out themolecular mechanics calculations. This work was supported in part (E.R. and A.L.S.) by the Netherlands Foundation for Chemical Research (SON) with financial aid from the Netherlands Organization for Scientific Research (NWO).

Supporting Information Available: Further details on the structure determination, including tables of atomic coordinates, all bond lengths and angles, and thermal parameters, for $(R, R)-3 b$, text giving NMR and GC-MS data on the catalysts and related compounds, and text giving full analytical data on the organic products of the addition reactions (17 pages). Ordering information is given on any current masthead page.

OM9701478 